OPEN ACCESS

Edited by:

Matthew S. Francis,

Umeå University, Sweden

Reviewed by:

Xiaohui Zhou

University of Connecticut, USA

Jeffrey $H$. Withey,

Wayne State University School of

Medicine, USA

Karla Satchell,

Northwestern University, USA

*Correspondence:

Saumya Raychaudhuri saumya@rocketmail.com

Received: 06 January 2017 Accepted: 02 March 2017 Published: 20 March 2017

Citation:

Bankapalli LK, Mishra RC and Raychaudhuri S (2017) VopE, a Vibrio cholerae Type III Effector, Attenuates the Activation of CWI-MAPK Pathway

in Yeast Model System.

Front. Cell. Infect. Microbiol. 7:82 doi: $10.3389 / f c i m b .2017 .00082$

\section{VopE, a Vibrio cholerae Type III Effector, Attenuates the Activation of CWI-MAPK Pathway in Yeast Model System}

\author{
Leela K. Bankapalli, Rahul C. Mishra and Saumya Raychaudhuri * \\ Molecular Biology and Microbial Physiology, Institute of Microbial Technology, Chandigarh, India
}

VopE, a mitochondrial targeting T3SS effector protein of Vibrio cholerae, perturbs innate immunity by modulating mitochondrial dynamics. In the current study, ectopic expression of VopE was found to be toxic in a yeast model system and toxicity was further aggravated in the presence of various stressors. Interestingly, a VopE variant lacking predicted mitochondrial targeting sequence (MTS) also exhibited partial lethality in the yeast system. With the aid of yeast genetic tools and different stressors, we have demonstrated that $\mathrm{VopE}$ and its derivative $\mathrm{VopE}^{\Delta \mathrm{MTS}}$ modulate cell wall integrity (CWI-MAPK) signaling pathway and have identified several critical residues contributing to the lethality of VopE. Furthermore, co-expression of two effectors VopE ${ }^{\Delta M T S}$ and VopX, interfering with the CWI-MAPK cellular pathway can partially suppress the VopX mediated yeast growth inhibition. Taken together, these results suggest that VopE alters signaling through the CWI-MAPK pathway, and demonstrates the usefulness of yeast model system to gain additional insights on the functionality of VopE.

Keywords: Vibrio cholerae, T3SS effector, GAPs, suppression analysis, yeast mitochondria, stressors, MAPK signaling pathway

\section{INTRODUCTION}

The effectiveness of a microbe as a pathogen is largely dependent on its ability to subvert the host defense mechanism. In many bacterial pathogens, the type 3 secretion system (T3SS) and associated effector proteins are utilized to hijack host immune surveillance, further allowing survival of the bacteria in hostile host environments. Multiple lines of converging evidences clearly demonstrate the evolution of unique functional domains and motifs in several T3SS effector proteins, that empower diverse pathogens to usurp disparate host cellular processes (Dean, 2011; Salomon et al., 2013).

A T3SS secretion system and 11 bona fide effector proteins with unique structural and functional features have been reported in Vibrio cholerae strains belonging to diverse serogroups and role of these effector proteins in pathogenesis have been studied in vitro and also in vivo using animal and yeast model system (Dziejman et al., 2005; Tam et al., 2007; Tripathi et al., 2010; Alam et al., 2011). One such effector protein VopE, a close homolog of the Yersinia T3SS effector protein YopE, disrupts the integrity of tight junctions by modulating actin homeostasis, thus promoting pathogenecity of $V$. cholerae strain AM-19226 (Tam et al., 2010; Shin et al., 2011). Furthermore, it has been demonstrated that VopE by virtue of a typical mitochondrial targeting sequence (MTS) at the N-terminus localizes to the mitochondria where it alters mitochondrial dynamics 
and modulates innate immune signaling by interfering with Miro GTPases (Suzuki et al., 2014). Sequence analysis reveals the existence of GTPase-activating protein (GAP) domain at the C-terminus of VopE (Suzuki et al., 2014). Such GAP domain is also reported in other T3SS effector proteins such as YopE (Yersinia pestis), SptP (Salmonella typhimurium), and ExoS (Pseudomonas aeruginosa) which are known to target the actin cytoskeleton in mammalian cells (Busch and Aktories, 2000). Though sequence based structural features predict that VopE shares structural homology with YopE, but VopE does not target actin cytoskeleton (Suzuki et al., 2014).

There is a growing appreciation of the utility of Saccharomyces cerevisiae, the budding yeast as a non-mammalian model system to identify and evaluate the functionality of diverse arrays of virulence factors from numerous pathogenic bacteria (Valdivia, 2004; Siggers and Lesser, 2008; Curak et al., 2009; Popa et al., 2016). Simple ectopic expression of virulence factors can lead to a variety of discernable phenotypes in yeast that help to build testable hypotheses regarding their function and roles in pathogenesis. There are seminal evidences where the function of numerous effector proteins (e.g., YopE, SipA, Tarp, VopX etc.) was first evaluated in the yeast model and documented later in mammalian systems (Von Pawel-Rammingen et al., 2000; Lesser and Miller, 2001; Galkin et al., 2002; Kumar et al., 2006; Sisko et al., 2006; Siggers and Lesser, 2008; Alam et al., 2011). There are instances where expression of certain effector proteins gave rise to different phenotypes in yeast system than mammalian system, thereby entailing additional function associated with a particular effector (Siggers and Lesser, 2008). For example expression of Map (T3SS effector protein of Escherichia coli) results in the formation of filopodia in mammalian cells but its expression in yeast model promotes the formation of large unbudded cells (Rodríguez-Escudero et al., 2005). Additionally, yeast has also been used as a model to gain new insights on mammalian proteins (Pereira et al., 2012).

The mitogen-activated protein kinase (MAPK) signaling pathways have been studied in great detail in S. cerevisiae (Hunter and Plowman, 1997; Gustin et al., 1998). The MAPK signaling pathway has been shown to be targeted by several T3SS effectors of diverse pathogenic bacteria. For example, HOG MAPK pathway of S. cerevisiae is targeted by VopA (Vibrio parahemolyticus), YopJ (Yersinia sp.), and HopX1 (Pseudomonas syringae) (Yoon et al., 2003; Trosky et al., 2004; Salomon et al., 2012). YopJ also targets the pheromone response MAPK pathway in the yeast model system (Yoon et al., 2003). The T3SS effector protein of $V$. cholerae, VopX has been reported to interfere with the functioning of the CWI-MAPK pathway (Alam et al., 2011; Seward et al., 2015). In sum, yeast model system reveals that MAPK signaling pathways are potential targets of T3SS effector proteins.

In this study, another T3SS effector protein of $V$. cholerae, VopE has been investigated using yeast as a model system. The results obtained clearly revealed that level of toxicity of VopE is dependent on yeast genetic background and is exacerbated in the presence of various stressors. Though mitochondrial localization of VopE is important for full toxicity, deletion of mitochondrial target sequence (MTS) still retained partial lethality. By employing different stressors coupled with $\beta$-galactosidase assay, VopE and its variant $\left(\operatorname{VopE}^{\Delta \mathrm{MTS}}\right)$ were found to interfere with MAPK pathway primarily affecting the functioning of cell wall integrity (CWI) pathway. Interestingly, screening yeast deletion library related to CWI cellular pathway identified hypersensitive strains. Furthermore, the present work also identified several critical residues contributing to VopE function and unveiled how co-expression of two effectors, VopE ${ }^{\triangle M T S}$ and VopX, targeting CWI-MAPK cellular pathway in an opposing manner can suppress the VopX mediated yeast growth inhibition.

\section{MATERIALS AND METHODS}

\section{Strains and Plasmids}

The strains and plasmids used in this study are listed in Table 1. E. coli strains Nova blue or $\mathrm{DH} 5 \alpha$ were used for general cloning. The E. coli strains were propagated at $37^{\circ} \mathrm{C}$ in Luria Broth (LB) with agitation or on LB agar plates. When appropriate, the growth medium was supplemented with ampicillin $(100 \mu \mathrm{g} / \mathrm{ml})$. S. cerevisiae strains were grown at $30^{\circ} \mathrm{C}$ in YPD $[1 \%(\mathrm{w} / \mathrm{v})$ yeast extract, $2 \%(\mathrm{w} / \mathrm{v})$ peptone, $2 \%(\mathrm{w} / \mathrm{v})$ glucose] broth or agar (2\%). Media ingredients were purchased from Himedia and Difco. Identity of all BY4741 deletion strains were verified by UP TAG (barcode) confirmation.

The vopE gene was amplified from the genomic DNA of $V$. cholerae strain $\mathrm{SC} 110$ using the gene specific primers and used to generate recombinant plasmids (Table 1). The conserved residues or regions of VopE were either deleted or substituted with alanine or glycine using Stratagene one step mutagenesis kit. The recombinant plasmid pESCLEU-VopE was used as a template for all mutagenesis reactions. The desired constructs were further transformed into S. cerevisiae strains.

For localization studies, all VopE constructs were Cterminally tagged with mCherry (from pmCherry-C1, Clonetech) by an overlapping PCR as described earlier (Tripathi et al., 2010). For mitochondrial visualization, COX4-GFP fragment was constructed by fusing a fragment encoding first 63 bases of COX4 to a gene encoding GFP (from pGREG575) by overlapping PCR method. This construct was further inserted into pRS413. This recombinant plasmid pCOX4-GFP was transformed into BY4741 to generate reporter strain BY4741-COX4-GFP. For Gem1 over expression, Gem1 gene was amplified from genomic DNA of BY4741 with NotIF/PacIR primers, and further inserted into pESCLEU-VopE to generate dual expression plasmid pESCLEU-VopE-Gem1. For VopX expression, vopX gene was amplified from the genomic DNA of V.cholerae strain SC110 using the gene specific primers, and subsequently inserted into NotI/PacI sites of pESCLEU or pESCLEU-VopE to generate recombinant plasmids. For protein detection, VopE constructs were tagged at C-terminus with 3XFLAG. All recombinant plasmids constructed in this study (Table 1) were confirmed by sequencing and maintained in E. coli strains. 
TABLE 1 | Strains and plasmids used in this study.

\begin{tabular}{lll}
\hline Strains/plasmids & Genotype/Description & Source/References \\
\hline E. coli & & Novagen \\
NovaBlue & E. coli K-12, recA endA, lac/q, lacY & Microbial Type Culture Collection \\
DH5 $\alpha$ & $F-\Phi 80 l a c Z \Delta M 15 \Delta($ lacZYA-argF) U169 recA1 endA1 hsdR17 (rK-, & and Gene Bank (MTCC) \\
V. cholerae & $m K+)$ phoA supE44 $\lambda$ - thi-1 gyrA96 relA1 & Tripathi et al., 2010 \\
SC110 & Non-O1/non-O139 strain of $V$. cholerae serogroup O34 & \\
\hline
\end{tabular}

\section{S. cerevisiae strains}

\begin{tabular}{|c|c|}
\hline BY4741 & MATa; his3 $\Delta$ 1; leu2 $\Delta 0$; met15 $\Delta 0$; ura3 $\Delta 0$ \\
\hline BY4741 $\Delta b c k 1$ & MATa; his $3 \Delta$ 1; leu2 $\Delta 0$; met15 $\Delta 0$; ura3 $\Delta 0$; bck1 $\Delta:: k a n M X 4$ \\
\hline BY4741 $\Delta$ slt2 & MATa; his3 $\Delta$ 1; leu2 $\Delta$ 0; met15 $\Delta$ 0; ura3 $\Delta$ 0; slt2 $\Delta:: k a n M X 4$ \\
\hline BY4741 Dire1 & MATa; his3 $\Delta$ 1; leu2 $\Delta 0$; met15 $\Delta 0$; ura3 $\Delta 0$; ire1 $\Delta:: k a n M X 4$ \\
\hline BY4741 $\Delta$ fus3 & MATa; his3 $\Delta$ 1; leu2 $\Delta$ 0; met15 $\Delta$ 0; ura3 $\Delta$ 0; fus $3 \Delta:: k a n M X 4$ \\
\hline BY4741 $\Delta$ kss 1 & MATa; his3 $\Delta$ 1; leu2 $\Delta$ 0; met15 $\Delta 0$; ura3 $\Delta 0$; kss1 $\Delta:$ :kanMX4 \\
\hline BY4741 $\Delta s m k 1$ & MATa; his3 $\Delta$ 1; leu2 $\Delta 0$; met15 $\Delta$ 0; ura3 $\Delta 0$; smk1 $\Delta:: k a n M X 4$ \\
\hline BY4741 $\Delta r / m 1$ & MATa; his3 $\Delta$ 1; leu2 $\Delta 0$; met15 $\Delta$ 0; ura3 $\Delta 0$; rlm1 $\Delta .:$ kanMX4 \\
\hline BY4741 $\Delta k d x 1$ & MATa; his3 $\Delta$ 1; leu2 $\Delta 0$; met15 $\Delta$ 0; ura3 $\Delta 0$; kdx1 $\Delta:$ :kanMX4 \\
\hline BY4741 syca1 & MATa; his3 $\Delta$ 1; leu2 $\Delta 0$; met15 $\Delta$ 0; ura3 $\Delta 0$; yca1 $\Delta:: k a n M X 4$ \\
\hline $\mathrm{BY} 4741 \Delta \mathrm{gem} 1$ & MATa; his3 $\Delta$ 1; leu2 $\Delta 0$; met15 $\Delta$ 0; ura3 $\Delta$ 0; gem1 $\Delta::$ kanMX4 \\
\hline BY4741 $\Delta d n m 1$ & MATa; his3 $\Delta$ 1; leu2 $\Delta 0$; met15 $\Delta$ 0; ura3 $\Delta 0$; dnm1 $\Delta::$ kanMX4 \\
\hline BY4741 $\Delta f z O 1$ & MATa; his3 $\Delta$ 1; leu2 $\Delta$ 0; met15 $\Delta$ 0; ura3 $\Delta$ 0; fzo1 $\Delta:: k a n M X 4$ \\
\hline BY4741 $\Delta m \operatorname{tg} 1$ & MATa; his3 $\Delta$ 1; leu2 $\Delta$ 0; met15 $\Delta$ 0; ura3 $\Delta 0$; mtg1 $\Delta:: k a n M X 4$ \\
\hline BY4741 $\Delta m t g 2$ & MATa; his3 $\Delta$ 1; leu2 $\Delta$ 0; met15 $\Delta$ 0; ura3 $\Delta 0 ;$ mtg2 $\Delta:: k a n M X 4$ \\
\hline BY4741 $\Delta h \circ g 1$ & MATa; his3 $\Delta$ 1; leu2 $\Delta$ 0; met15 $\Delta$ 0; ura3 $\Delta 0$; hog1 $\Delta:: k a n M X 4$ \\
\hline BY4741 $\Delta m k k 1$ & MATa; his3 $\Delta$ 1; leu2 $\Delta 0$; met15 $\Delta$ 0; ura3 $\Delta 0$; mkk1 $\Delta:: k a n M X 4$ \\
\hline $\mathrm{BY} 4741 \Delta m k k 2$ & MATa; his3 $\Delta$ 1; leu2 $\Delta 0$; met15 $\Delta 0$; ura3 $\Delta$ 0; mkk2 $\Delta:: k a n M X 4$ \\
\hline BY4741 $\Delta m g m 1$ & MATa; his3 $\Delta$ 1; leu2 $\Delta$ 0; met15 0 ; ura3 $\Delta 0$; mgm1 $\Delta:: k a n M X 4$ \\
\hline W303-1A & $\begin{array}{l}\text { MATa leu2-3,112 his3-11,15 ade2-1 ura3-1 trp1-1 can1-100 GAL } \\
\text { SUC2 }\end{array}$ \\
\hline
\end{tabular}
Bankapalli et al., 2015
EUROSCARF
EUROSCARF
EUROSCARF
EUROSCARF
EUROSCARF
EUROSCARF
EUROSCARF
EUROSCARF
EUROSCARF
EUROSCARF
EUROSCARF
EUROSCARF
EUROSCARF
EUROSCARF
EUROSCARF
EUROSCARF
EUROSCARF
EUROSCARF
Tripathi et al., 2010

\section{Plasmids}

\begin{tabular}{|c|}
\hline pESCLEU \\
\hline pGML10 \\
\hline pAMU10 \\
\hline pRS413 \\
\hline pESCLEU-VopE \\
\hline pESCLEU-VopE \\
\hline pESCLEU-VopE ${ }^{\Delta 24-80}$ \\
\hline pESCLEU-VopE ${ }^{\Delta 1-80}$ \\
\hline pESCLEU-VopE ${ }^{\Delta M T S}$ \\
\hline pESCLEU-VopE ${ }^{\Delta M T S ~ R 125 A ~}$ \\
\hline pESCLEU-VopE ${ }^{\Delta 119-121}$ \\
\hline pESCLEU-VopE ${ }^{\Delta 159-167}$ \\
\hline pESCLEU-VopE ${ }^{A 120 G}$ \\
\hline pESCLEU-VopE $E^{T 129 A}$ \\
\hline pESCLEU-VopE ${ }^{Q 161 A}$ \\
\hline pESCLEU-VopEG163A \\
\hline pESCLEU-VopE ${ }^{T 164 A}$ \\
\hline pESCLEU-VopE ${ }^{F 110 A}$ \\
\hline pESCLEU-VopEF162A \\
\hline pESCLEU-VopEV173A \\
\hline
\end{tabular}

$2 \mu$, GAL1/GAL10,LEU2

CEN6/ARSH4, GAL1,LEU2

CENG/ARSH4,ADH1,URA3

CEN6/ARSH4,TEF,HIS3

615 bp vopE gene fragment amplified from genomic DNA of $V$. cholerae SC110 with Xhol/Nhel primers by PCR and cloned into similarly digested pESCLEU under GAL1 promoter

VopE harboring $A$ in place of $R$ at position 125

VopE harboring deletion for 24-80

VopE harboring deletion for 1-80

VopE harboring deletion for 1-23

VopE harboring deletion for 1-23, A in place of $\mathrm{R}$ at position 125

VopE harboring deletion for 119-121

VopE harboring deletion for 159-167

VopE harboring $\mathrm{G}$ in place of $\mathrm{A}$ at 120

VopE harboring A in place of $\mathrm{T}$ at 129

VopE harboring $A$ in place of $Q$ at 161

VopE harboring $A$ in place of $G$ at 163

VopE harboring A in place of $\mathrm{T}$ at 164

VopE harboring $A$ in place of $F$ at 110

VopE harboring $A$ in place of $F$ at 162

VopE harboring $A$ in place of $V$ at 173
Agilent

Technologies

RIKEN

RIKEN

Gift from Dr. Deepak Sharma, Institute of Microbial Technology This study

This study

This study

This study

This study

This study

This study

This study

This study

This study

This study

This study

This study

This study

This study

This study 


\section{TABLE 1 | Continued}

\begin{tabular}{|c|c|c|}
\hline Strains/plasmids & Genotype/Description & Source/Reference \\
\hline pESCLEU-mCherry & $\begin{array}{l}\text { mCherry gene fragment was inserted into pESCLEU at Xhol, Nhel sites } \\
\text { under GAL1 promoter }\end{array}$ & This study \\
\hline pESCLEU-VopE-mCherry & $\begin{array}{l}\text { vopE-mCherry fragment was inserted into pESCLEU at Xhol, Nhel sites } \\
\text { under GAL1 promoter }\end{array}$ & This study \\
\hline 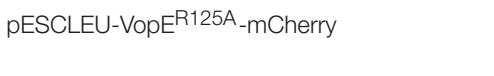 & $\begin{array}{l}\text { vop } E^{\mathrm{R} 125 \mathrm{~A}}-m \text { Cherry fragment was inserted into pESCLEU at Xhol, Nhel } \\
\text { sites under GAL1 promoter }\end{array}$ & This study \\
\hline pESCLEU-VopE ${ }^{\Delta M T S}$-mCherry & $\begin{array}{l}\text { vopE }{ }^{\triangle M T S_{-}} \text {Cherry fragment was inserted into pESCLEU at Xhol, Nhel } \\
\text { sites under GAL1 promoter }\end{array}$ & This study \\
\hline pESCLEU-Gem1 & $\begin{array}{l}1.99 \mathrm{~kb} \text { Gem1 gene fragment amplified from genomic DNA of BY } 4741 \\
\text { with Not//Pacl primers by PCR and cloned into similarly digested } \\
\text { pESCLEU under GAL10 promoter }\end{array}$ & This study \\
\hline pESCLEU-VopE-Gem1 & $\begin{array}{l}\text { vopE (Xhol/Nhel) and Gem1 (Notl/Pacl) fragments were cloned in } \\
\text { pESCLEU under GAL1 and GAL10 promoters, respectively }\end{array}$ & This study \\
\hline pESCLEU-VopX & $\begin{array}{l}\text { vopX obtained by Not//Pacl primers inserted into pESCLEU under } \\
\text { GAL10 promoter }\end{array}$ & This study \\
\hline pESCLEU-VopE-VopX & $\begin{array}{l}\text { vopE (Xhol/Nhel) and vopX (Not//Pacl) fragments were cloned in } \\
\text { pESCLEU under GAL1 and GAL10 promoters respectively }\end{array}$ & This study \\
\hline pESCLEU-VopE ${ }^{\Delta M T S}$-VopX & $\begin{array}{l}\text { vopE } \triangle M T S \text { (Xhol/Nhel) and vopX (Notl/Pacl) fragments were cloned in } \\
\text { pESCLEU under GAL1 and GAL } 10 \text { promoters, respectively }\end{array}$ & This study \\
\hline pESCLEU-VopE ${ }^{\Delta M T S}$ R125A_VopX & $\begin{array}{l}\text { vopE } \\
\text { cloned in pESCLEU under GAL1 and GAL10 promoters, respectively }\end{array}$ & This study \\
\hline pGML10-VopE & $\begin{array}{l}615 \text { bp vopE gene fragment amplified from pESCLEU-VopE with } \\
\text { BamHI/Ecorl primers by PCR and cloned into similarly digested } \\
\text { pGML10 under GAL1 promoter }\end{array}$ & This study \\
\hline pAMU10-VopE & $\begin{array}{l}615 \text { bp vopE gene fragment amplified from pESCLEU-VopE with } \\
\text { BamHI/ECorl primers by PCR and cloned into similarly digested } \\
\text { pAMU10 under } A D H 1 \text { promoter }\end{array}$ & This study \\
\hline pRS413-COX4-GFP & $\begin{array}{l}\text { Amplified COX4-GFP fragment cloned into Xbal, BamHI sites of pRS413 } \\
\text { under TEF promoter }\end{array}$ & This study \\
\hline pKT760 & HOG 8xCRE-lacZ, TRP1 & Gift from Dr. Guido Sessa, Tel \\
\hline p1434 & CWI 2xRIm1-lacZ, URA3 & Aviv University, Israel \\
\hline pMCZ & UPR, UPRE-lacZ, URA3 & \\
\hline Pheromone MAPK pathway Reporter plasmid & Pheromone, $P_{\text {FUS1-lacZ, URA3 }}$ & \\
\hline
\end{tabular}

\section{Yeast Growth and Viability Assays}

Yeast growth assays were performed as described earlier (Tripathi et al., 2010; Bankapalli et al., 2015). Briefly, overnight cultures of all recombinant strains in selective $\mathrm{SC}^{\text {Raf }}$ medium were diluted and grown again in same media at $30^{\circ} \mathrm{C}$ until exponential phase $\left(\mathrm{OD}_{600} \sim 0.8-1.0\right)$. Effect of the expression of VopE, its derivatives and VopX on the growth of S. cerevisiae strains was examined by spotting equal number of cells onto $\mathrm{SC}$ and $\mathrm{SC}^{\mathrm{Gal}}$ plates lacking the corresponding auxotrophic markers to maintain the plasmids. When necessary, liquid growth induction was done for $6 \mathrm{~h}$ by adding galactose (2\%) to cultures before spotting. Growth was monitored after $60-70 \mathrm{~h}$ at $30^{\circ} \mathrm{C}$ and photographed accordingly. Liquid growth assay was done as described earlier (Bankapalli et al., 2015). For yeast viability plating assay (cfu), recombinant stains carrying VopE or its variants were grown overnight in selective $\mathrm{SC}^{\mathrm{Raf}}$ media. Cultures were again diluted to $\mathrm{OD}_{600} 0.1$ in fresh media and incubated up to $\mathrm{OD}_{600} \sim 1.0$ where cultures were resuspended in selective $\mathrm{SC}^{\mathrm{Gal}}$ media. At different times after induction, aliquots were removed, and serial dilutions were plated on selective SC solid media. Plates were incubated for $2-3$ days at $30^{\circ} \mathrm{C}$ before viable colonies were counted (Salomon et al., 2011).

\section{Yeast $\beta$-Galactosidase Assay}

S. cerevisiae strain BY4741 harboring pESCLEU-VopE (BY4741VopE) was transformed with various $l a c Z$ reporter plasmids as listed in Table 1 (2XRlm1-lacZ, P PUs1-lacZ, and UPRElac $Z$ ). The HOG pathway related lacZ reporter plasmid (HOG 8XCRE-lacZ) was transformed into W303-1A strain harboring pESCLEU-VopE (W303-VopE). All the plasmids were obtained as gift from Dr. Guido Sessa, Tel Aviv University, Tel Aviv, Israel (Salomon et al., 2012). For $\beta$-galactosidase assay, we followed the published protocol (Salomon et al., 2012). Briefly, overnight cultures of recombinant strains were diluted in selective medium containing raffinose (2\%) and grown to $\mathrm{OD}_{600}$ 0.6-0.9. Galactose (2\%) was added and incubated for $6 \mathrm{~h}$. Equal amount of cultures were then distributed into two tubes. In one set, stressors were added and kept for stipulated period as given. To activate the HOG pathway, $0.5 \mathrm{M} \mathrm{NaCl}$ for $1 \mathrm{~h}$; to activate the CWI pathway, $3 \mathrm{mM}$ caffeine for $4 \mathrm{~h}$; to stimulate the UPR, $2 \mathrm{mM}$ DTT for 
$4 \mathrm{~h}$; to induce the pheromone signaling pathway, $5 \mu \mathrm{M} \alpha$ factor for $2 \mathrm{~h}$. Cells were finally harvested and subjected to rapid permeabilization procedure as described earlier (Kippert, 1995). Activity is reported as percentage of Miller units.

\section{Preparation of Yeast Extracts and Immunoblot Analysis}

The immunoblot analysis was carried out based on previous work (Tripathi et al., 2013; Bankapalli et al., 2015). All the recombinant yeast strains carrying wild type $\mathrm{VopE}$ and its congeners were grown in selective $\mathrm{SC}^{\mathrm{Raf}}$ medium at $30^{\circ} \mathrm{C}$ until mid-log phase. The cultures were then diluted in selective induction media $\left(\mathrm{SC}^{\mathrm{Gal}}\right)$. After $6 \mathrm{~h}$ of induction, cultures were pelleted and whole cell protein extracts were prepared by adopting a published protocol (Zhang et al., 2011). Equal amount of protein samples were fractionated by SDS-polyacrylamide gel electrophoresis using $12 \%$ polyacrylamide gel and transferred to Immobilon$\mathrm{P}$ Transfer Membrane (Millipore). Membrane was probed with either Monoclonal anti-FLAG M2-Peroxidase (HRP) Clone M2 (Sigma) antibody or anti-Porin (yeast mitochondria) Monoclonal Antibody (Invitrogen, Mitosciences). The primary antibody was detected using a horseradish peroxidase conjugated anti-mouse antibody (Millipore) and blot was developed with Luminata ${ }^{\mathrm{TM}}$ Forte Western HRP substrate.

\section{Yeast Confocal Microscopy and Subcellular Fractionation}

To investigate the localization of VopE and its mutagenized congeners, recombinant yeast strains harboring these constructs (Table 1) were harvested after galactose induction. Samples were observed by Confocal Laser Scanning Microscope (Nikon A1R). For isolation of mitochondria, yeast cells containing vector (pESCLEU), or VopE were grown in selective SC media and grown again in $500 \mathrm{ml}$ of fresh media till $\mathrm{OD}_{600}$ was 1.5. Subsequently, cells were harvested and expression of VopE was induced by re-suspending the pellet in $500 \mathrm{ml}$ of selective SC ${ }^{\mathrm{Gal}}$ media for $6 \mathrm{~h}$. Purification of yeast mitochondria was performed according to standard procedure (Gregg et al., 2009).

\section{RESULTS}

\section{Ectopic Expression of VopE in S. cerevisiae Affects Cell Growth}

Several $V$. cholerae strains belonging to non-O1, non-O139 serogroups (laboratory collection) were examined for the presence of the vopE gene. The gene fragment was PCR amplified and cloned under the control of GAL1 promoter in the high copy number vector pESCLEU to generate recombinant plasmid pESCLEU-VopE. Next, VopE (A33_1662) was ectopically expressed in a $S$. cerevisiae strain W303-1A. Under inducing condition, spotting on solid agar media exhibited no growth inhibition, where as in liquid media strong growth inhibition was observed (Figure 1A, left and right panels). As reported, certain effectors exhibit an altered toxicity in solid and liquid growth assay conditions in yeast model system (Kramer et al., 2007; Siggers and Lesser, 2008; Antic et al., 2014). Interestingly, it has been documented that effector driven growth inhibition is dependent on different yeast genetic backgrounds (RodríguezPachón et al., 2002; Bénit et al., 2010; Salomon et al., 2011). To ascertain the function of VopE in another genetic background, we transformed the pESCLEU-VopE recombinant construct into strain BY4741. An increase in lethality of VopE in BY4741 genetic background over that in W303-1A was observed (Figure 1B left and right panels).

Activity of bacterial effectors carrying GAP domain largely depend on arginine residue, referred as the arginine finger. VopE is a member of bacterial GAP effector family and also carries a conserved arginine along with additional GAP domain features. To ascertain the contribution of arginine at position 125 in VopE mediated toxicity in yeast system, we exchanged arginine with alanine and evaluated the lethality of recombinant $\operatorname{VopE}^{\mathrm{R} 125 \mathrm{~A}}$ variant. The data clearly demonstrated significant loss in lethality of $\mathrm{VopE}^{\mathrm{R} 125 \mathrm{~A}}$ variant, thereby underscoring the importance of arginine residue in the functionality of VopE in yeast system (Figure 1B left panel). To investigate in vivo protein stability, wild type and VopE ${ }^{\mathrm{R} 125 \mathrm{~A}}$ were C-terminally tagged with FLAG epitope and western blot analysis using anti-FLAG antibody was carried out (Zhang et al., 2011; Tripathi et al., 2013). The results indicated that VopE and $\operatorname{VopE}^{\mathrm{R} 125 \mathrm{~A}}$ were found to be stable (Figure 2C). The viability of yeast carrying VopE or VopE $E^{\mathrm{R} 125 \mathrm{~A}}$ was also determined by CFU assay at different time periods up to $24 \mathrm{~h}$. A gradual decrease in number of viable cells suggesting that growth inhibition caused by VopE is due to loss of viability (Figure 1D).

Although, bacteria encode different T3SS effector proteins, quantity of each effector translocated into host varies in amount during infection. Earlier studies have clearly demonstrated that low level expression of effector proteins increases the specificity while high level expression promotes sensitivity of inhibition in yeast model system (Slagowski et al., 2008). In some cases, it is also surmised that high level expression may result in non-specific toxic effects (Salomon et al., 2012). Therefore, we wanted to ascertain whether low level expression of VopE maintains similar toxicity as presented in the preceding section, the gene encoding wild type VopE was cloned in pGML10, a low copy number vector (Table 1). Unlike yeast harboring pESCLEU-VopE construct, recombinant yeast cells transformed with pGML10-VopE show mild growth defect, further indicating that VopE toxicity depends on the level of expression (Figures 1C and 1B right panel). As evidenced, several effector proteins exhibit toxicity only when expressed at high level (Slagowski et al., 2008). During analyzing the function of various Legionella pneumophila effectors in yeast system, it appears that toxicity of some effectors manifests only at high level while others are independent of the level of expression (Havey and Roy, 2015).

\section{VopE Variant Lacking Mitochondrial Target Sequence (VopE ${ }^{\Delta M T S}$ ) Retains Partial Lethality}

VopE contains predicted MTS spanning N-terminal 23 amino acids and removal of this stretch has been reported to affect VopE localization to mitochondria (Suzuki et al., 2014). To investigate 

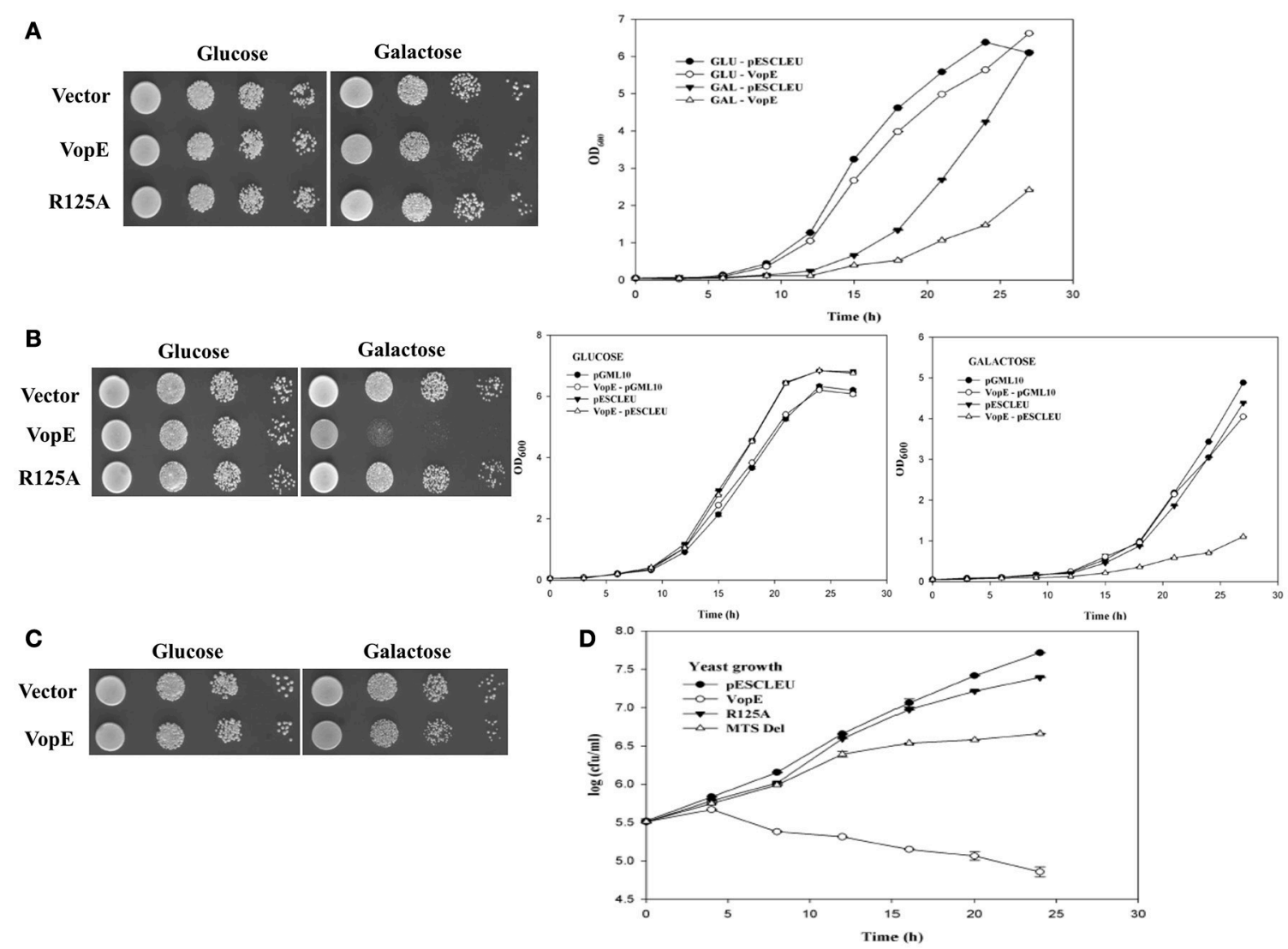

FIGURE 1 | Effect of VopE on Yeast growth. (A) W303-1A transformants carrying VopE or VopE ${ }^{R 125 A}$ under control of GAL1 promoter were subjected to spotting on selective solid media containing glucose (repressor) or galactose (inducer). Liquid growth assay shown on right panel. Yeast harboring pESCLEU (high copy vector) treated as control. (B) Similar experiment was performed in BY4741 genetic background with pESCLEU cloning vector. (C) BY4741 transformants harboring pGML10 (low copy vector) or VopE were subjected to spotting under selective solid media containing glucose or galactose conditions. Liquid growth assay shown in (B) right panel. (D) For yeast growth viability analysis, BY4741 strains carrying VopE constructs were sampled at each time point and 10-fold serial dilutions were plated on glucose plate to count viable cells. Error bar indicates standard deviation from mean. Each experiment repeated three times with similar results.

the cellular fate of VopE variant lacking MTS (henceforth known as VopE ${ }^{\Delta \mathrm{MTS}}$ ), growth of recombinant strain BY4741VopE $^{\triangle M T S}$ carries a VopE ${ }^{\Delta M T S}$ in high copy number vector was examined under inducing condition. Solid agar spotting data indicate that $\left(\mathrm{VopE}^{\Delta \mathrm{MTS}}\right)$ retains some ability to intoxicate yeast cells albeit less than wild type protein VopE (Figure 2B, left panel). The spotting data were further corroborated by liquid growth assay where a similar trend of growth inhibition was noticed (Figure 2B, right panel). To ensure in vivo stability of $\mathrm{VopE}^{\triangle \mathrm{MTS}}$, western blot was performed by using anti-FLAG antibody (Figure 2C). In growth viability assay, number of growing cells increased for first $12 \mathrm{~h}$, and then maintained as constant number of viable cells (Figure 1D).

\section{Identification of Additional Conserved Structural Unit Contributing VopE Activity}

Structural and sequence analysis reveal certain unique features essential for optimal performance of different bacterial GTPaseactivating proteins (GAPs) (Litvak and Selinger, 2003). For example, there are several conserved residues and two bulge regions (I \& II) in bacterial GAPs whose mutual interactions maintain the precise orientation of the critical arginine and catalytic efficiency of the GAPs. The catalytic arginine residue within the bulge I interacts with the nucleotide phosphate and with the conserved residues of bulge II (Stebbins and Galan, 2000; Wurtele et al., 2001; Litvak and Selinger, 2003). Sequence alignment of VopE with other bacterial GAPs identified bulge II region (Figure 3A). To examine the importance of this region in VopE function, the bulge II region (amino acids $159-167)$ was deleted and the activity of $\operatorname{VopE}^{\Delta 159-167}$ variant was examined in yeast strain BY4741. A loss of lethality was observed in the yeast strain carrying the VopE ${ }^{\Delta 159-167}$ variant (Figure 3B) further corroborating the importance of bulge II region in VopE function. Next, we turned our attention on other amino acids $\left(\mathrm{V}^{119}, \mathrm{~A}^{120}, \mathrm{~N}^{121}, \mathrm{~T}^{129}, \mathrm{Q}^{161}, \mathrm{G}^{163}, \mathrm{~T}^{164}\right)$ predicted to involve in network of multiple interactions (Figure 3A). A series of VopE variants carrying alanine substitutions (T129A, Q161A, G163A, and T164A), glycine substitution (A120G) or VAN deletion $(\Delta 119-121)$ were constructed and their effect was examined in yeast. Significant loss in lethality of VopE 
A

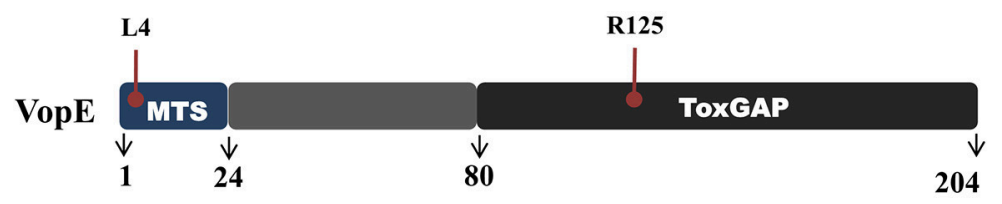

B
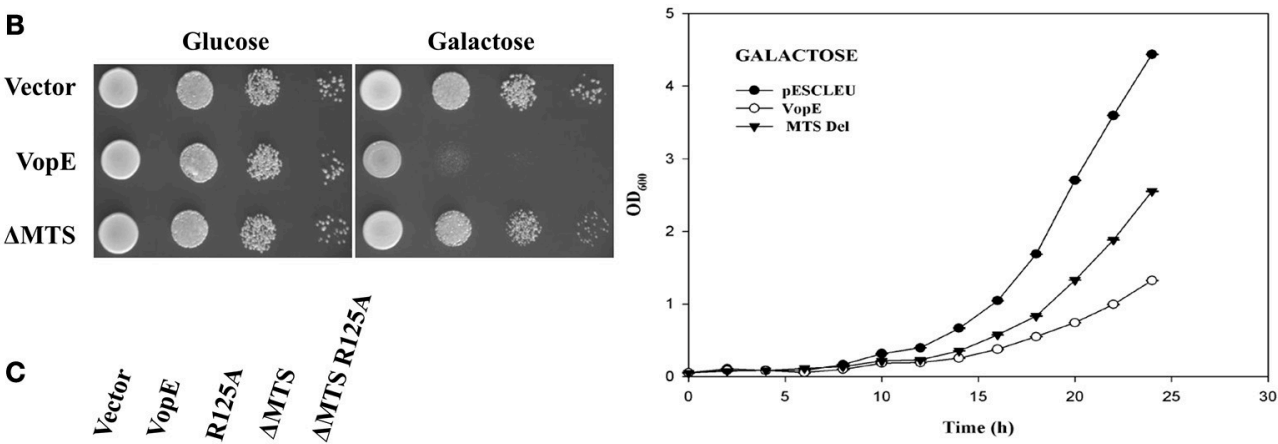

C

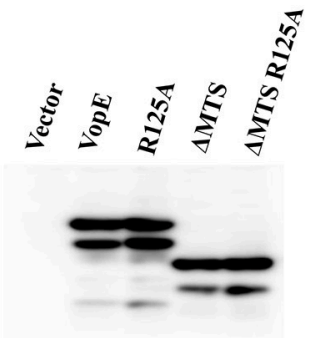

Time (h)

FIGURE 2 | VopE ${ }^{\Delta M T S}$ induced yeast growth inhibition. (A) Schematic representation of VopE domain or motif (B) BY4741 strains carrying pESCLEU or $V_{0 p E^{\Delta M T S}}$ were spotted on solid selection media containing glucose or galactose (left panel). Same cultures also inoculated in liquid selection media containing galactose (right panel). (C) In vivo stability of VopE-3XFLAG and its derivatives confirmed by immunoblot using anti-FLAG antibody.
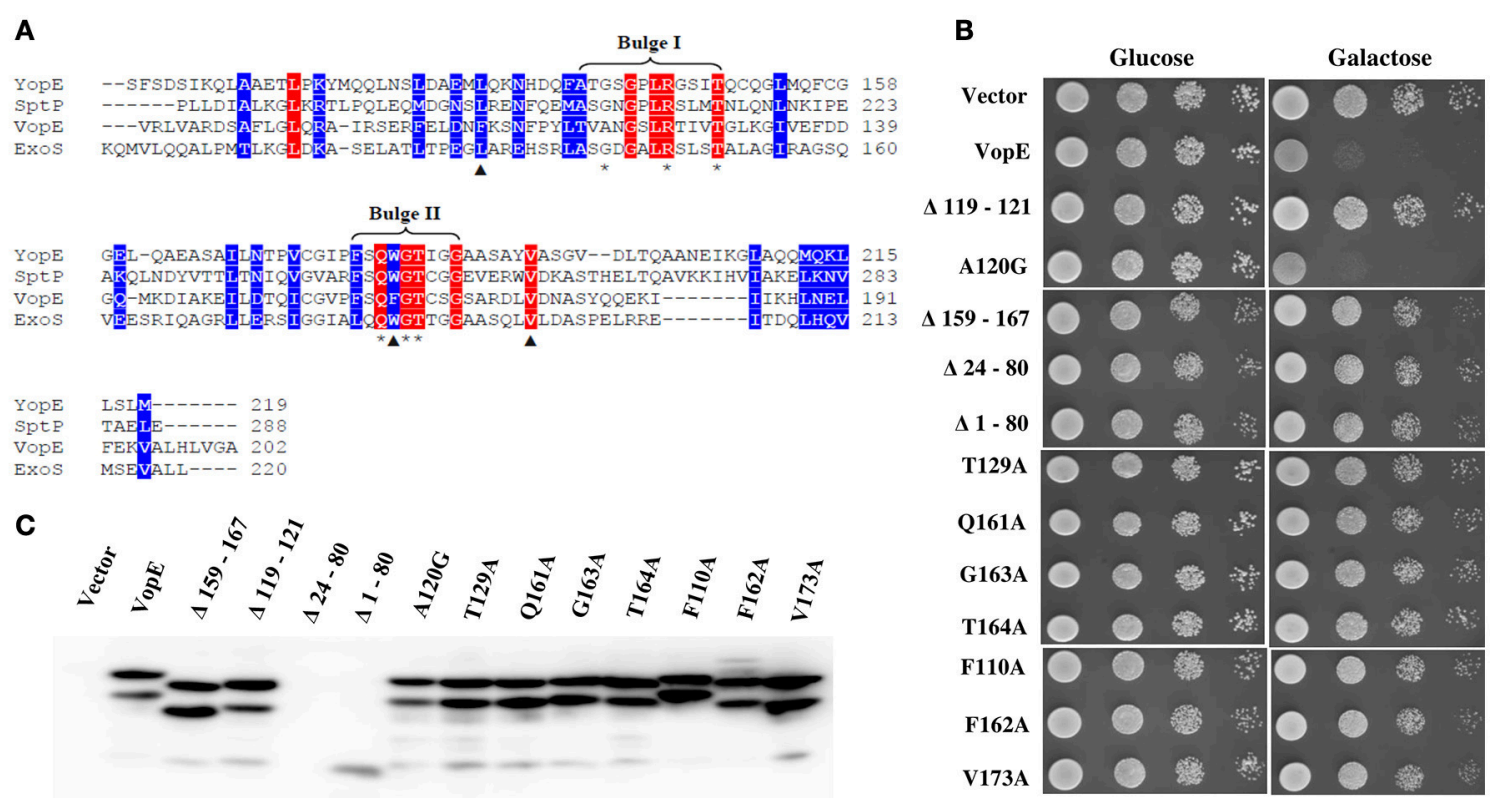

FIGURE 3 | Identification of residues and regions of VopE contributed in yeast toxicity. (A) Alignment of VopE along with other bacterial GTPase-activating protein sequences as carried out by Clustal Omega. Conserved and semi-conserved amino acid positions are highlighted with red and blue respectively. Predicted amino acids $\left(^{*}\right)$ involved in multiple interactions with unknown yeast target protein(s) or selected hydrophobic amino acids $(\boldsymbol{\Delta})$ are substituted with alanine or glycine. The GenBank identifiers and species name are as follows: YopE [31795304|Yersinia pestis]; SptP[16421425|Salmonella typhimurium str. LT2]; VopE [254285224|Vibrio cholerae AM19226]; ExoS [450297| Pseudomonas aeruginosa]. (B) BY4741 cultures carrying a vector, either pESCLEU or VopE variants were 10 -folded serial diluted and subjected to spotting on selective solid media containing glucose or galactose. (C) Expression of VopE-3XFLAG variants verified by western blot using anti-FLAG antibody. 
alanine (T129A, Q161A, G163A, T164A) and deleted ( $\triangle$ VAN) variants (Figure 3B), thereby indicating the significance of these interacting residues in maintaining VopE function in addition to arginine ${ }^{125}$ residue. It should be noted that toxicity of VopE variant harboring glycine at position $120\left(\mathrm{VopE}^{\mathrm{A} 120 \mathrm{G}}\right)$ remains unperturbed.

In addition to the residues posited in bulge I and II regions, there are residues participating in the formation of hydrophobic core in the GAP domain of SptP (Stebbins and Galan, 2000). Based on Clustal Omega alignment of VopE with SptP, ExoS, and YopE, three amino acids such as $\mathrm{F}^{110}, \mathrm{~F}^{162}$, and $\mathrm{V}^{173}$ were selected that might contribute to the formation of hydrophobic core of VopE (Figure 3A). Subsequent replacement of these amino acids with alanine resulted in loss of functionality of VopE (Figure 3B). Interestingly, non-conserved region might also contribute to the function of any given protein (Sampath et al., 2003). Indeed, when a non-conserved region spanning 24-80 amino acids (Figure 2A) was deleted, the resultant $\operatorname{VopE}^{\Delta} 24-80$ variant was found to be non-lethal in yeast model system (Figure 3B). Collectively, our effort led to the identification of several GAP domain associated residues and non-conserved region contributing to the functionality of VopE. To examine in vivo stability, western blot analysis of recombinant yeast strains harboring wild type and different VopE variants was carried out by using anti-FLAG antibody. We found that all the VopE derivatives were stable under in vivo condition except $\mathrm{VopE}^{\Delta 24-80}$ and $\mathrm{VopE}^{\Delta 1-80}$ (Figure 3C).

\section{Mitochondrial Localization of VopE in S. cerevisiae}

To examine mitochondrial localization of VopE in yeast model, a yeast reporter strain BY4741-COX4-GFP was first constructed by transforming pCOX4-GFP in S. cerevisiae BY4741. COX4-GFP fusion protein (targeted to mitochondrial matrix) has been used to visualize mitochondrial morphology in yeast (Otsuga et al., 1998). Next, pVopE-mCherry was transformed into BY4741COX4-GFP to generate BY4741-COX4-GFP-VopE-mCherry. In addition, VopE variants fused with mCherry (Table 1) were also transformed into BY4741-COX4-GFP. Upon induction, VopEmCherry conferred growth inhibition in BY4741-COX4-GFPVopE-mCherry (Figure S1), thus indicating that the fusion of mCherry at the C-terminus of VopE did not alter its activity. To visualize localization of mCherry tagged variants, the recombinant strains were harvested at $6 \mathrm{~h}$ following the addition of galactose and visualized by confocal microscopy. Similar to previous reports using mammalian cell lines, in yeast system also VopE and VopE $E^{\mathrm{R} 125 \mathrm{~A}}$ localize to mitochondria whereas $\mathrm{VopE}^{\Delta \mathrm{MTS}}$ was detected in the cytosol (Figure 4A). Localization of VopE in mitochondria was further confirmed by sub cellular fractionation where presence of VopE-3XFLAG signal in yeast mitochondrial fraction was detected by immunoblot with antiFLAG antibody (Figure 4B).

Certain P. syringae pv. tomato DC3000 effectors (HopAA11, HopAM1, HopAD1 etc.) when expressed in yeast have been shown to impair respiration and their toxicity enhanced on ethanol glycerol (EG) selective media (Munkvold et al., 2008). As
VopE targets to mitochondria, it was therefore conceivable that VopE may alter respiration in yeast and show enhance killing of yeast cells on glycerol. But spotting of recombinant yeast strain harboring VopE cloned under constitutive or inducible promoters did not show any enhanced killing of yeast cells on selective media containing glycerol (2\%; Figure 4C), thus indicating VopE does not impair yeast respiration.

\section{VopE Maintains Lethality in Yeast Mitochondrial GTPase Deletion Strains}

Inhibition of mitochondrial clustering by VopE is mediated through the inactivation of Miro GTPases (Suzuki et al., 2014). The mammalian miro Rho GTPase ortholog in the budding yeast is Gem1p (Frederick et al., 2004). Like other miro proteins, Gem1p also contains two GTPase domains, a pair of calcium binding EF-hand motifs and C-terminal transmembrane (TM) domain. Both GTPase domains and EF-hand motifs are essential for Gemlp to maintain mitochondrial dynamics (Frederick et al., 2004). To examine whether the VopE dependent lethality in yeast system was also mediated by the Gem1p (yeast Miro GTPase), VopE was transformed into the yeast strain lacking Gem1p, BY4741 $\Delta$ gem 1 (Table 1) and growth was assayed after VopE expression. In addition, Gem 1 was also over expressed in wild type yeast harboring VopE. Unexpectedly, VopE expression caused lethality in the gem 1 deleted yeast strain and gem 1 over expressed strain (Figures 5A,B). Conversely, Gem1, the yeast Miro GTPase is not targeted by VopE.

A battery of cellular components including several GTPases namely mitochondrial Rho GTPases (Miro I and Miro II), Fzo/mitofunsins (Mfn1 and Mfn2), Dnm1/Drp1/Dlp1, Mgm1/Opa1/Msp1 contributing to mitochondrial dynamics have been identified in yeast, flies, worms, and mammals (Shaw and Nunnari, 2002; Frederick and Shaw, 2007). VopE expression in a number of mitochondrial GTPase yeast deletion strains $(\Delta d n m 1, \Delta f z o 1, \Delta m g m 1, \Delta m t g 1, \Delta m t g 2)$ produced lethality similar to that produced by VopE expression in the wild type yeast strain (Figure 5A).

\section{VopE Mediated Yeast Growth Inhibition Was Exacerbated in the Presence of Stressors: The Signaling Pathway}

Many translocated bacterial effector proteins do not exhibit lethality in yeast model system either due to non-conservation of targets between yeast and mammalian system or because target (s) is conserved but it is dispensable and not rate limiting for yeast growth under normal conditions (Slagowski et al., 2008; Salomon et al., 2011). In latter cases, certain compounds, or environmental conditions known as "stressors" have been shown to increase the sensitivity of yeast strains toward different effectors and aid in the identification of effector mediated growth-retardation traits (Siggers and Lesser, 2008). The commonly employed stressors are (i) caffeine, a purine analog exerts pleiotropic effects in yeast and activates the CWI MAP kinase pathway. The molecule is highly toxic to the mutants of CWI pathway and Tor pathway (Parsons et al., 2004; Kuranda et al., 2006); (ii) Sorbitol, an osmotic stressor activates HOG (high osmolarity glycerol) MAP kinase pathway 


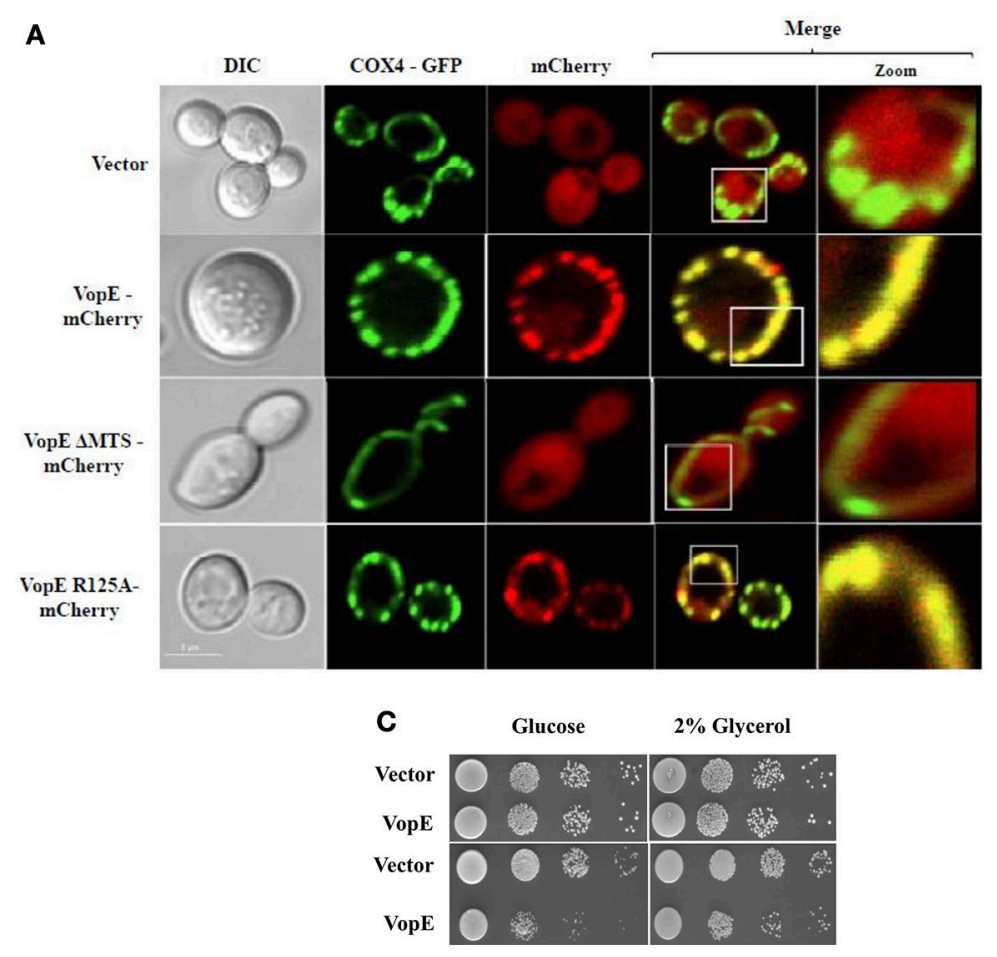

\section{B}

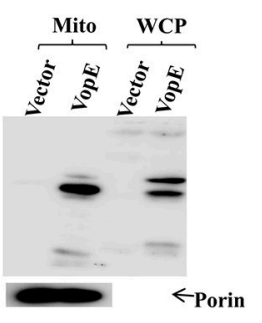

FIGURE 4 | VopE targeted to yeast mitochondria and does not impair respiration. (A) Plasmids encoding mCherry or VopE-mCherry variants were introduced into yeast reporter strain BY4741-COX4-GFP. Mid-log phase cells were induced for $6 \mathrm{~h}$ by the addition of galactose. Mitochondria were visualized by COX4-GFP (targeting to mitochondrial matrix). Cells were examined by confocal laser scanning microscopy to monitor the localization patterns of VopE-mCherry constructs. Scale bar equals to $5 \mu \mathrm{m}$. (B) Detection of VopE-3XFLAG in mitochondrial fraction and whole cell lysate of $6 \mathrm{~h}$ galactose induced cultures with anti-FLAG antibody. Mitochondrial fraction was confirmed with anti-porin antibody. (C) BY4741 transformants expressing VopE either constitutive (pAMU10, low copy vector, top panel) or inducible (pESCLEU, high copy vector, bottom panel) were subjected to spotting on selective solid media containing glucose or $2 \%$ glycerol. For liquid growth induction, liquid cultures were pretreated with galactose for $6 \mathrm{~h}$ before spotting.

and toxic to mutants of the HOG MAPK pathway (Gustin et al., 1998; Hohmann, 2002); (iii) $\mathrm{NaCl}$, an osmotic and ionic stressor that exhibits high level toxicity to the mutants of HOG MAPK pathway and ion homeostasis (Gustin et al., 1998; Hohmann, 2002; Auesukaree et al., 2009); (iv) tunicamycin, an inhibitor of protein glycosylation shows extreme toxicity to the mutants of unfolded protein response (UPR) pathway and mutants with cell wall defects (Parsons et al., 2004); (v) DTT, a reducing agent, is also known to induce ER stress (Papa et al., 2003; Bosis et al., 2011); (vi) $37^{\circ} \mathrm{C}$ heat stress, causes pleiotropic effects in yeast (Auesukaree et al., 2009). It has also been demonstrated that stressors also suppress the toxic activity of certain effectors. For example, lethality of Coxiella burnetii effector CBU0388-CetCb2 has been shown to be repressed by caffeine (Lifshitz et al., 2014).

Since VopE showed no toxicity in S.cerevisiae strain W303$1 \mathrm{~A}$ as compared to BY4741 in spotting assay (Figures 1A,B), the effect of various stressors on both $S$. cerevisiae strains W303-1A and BY4741 harboring VopE was next examined. For this purpose, the yeast strains were grown in the presence of some established stressors like caffeine (3 mM), $\mathrm{NaCl}$ $(0.5 \mathrm{M})$, sorbitol $(1 \mathrm{M})$, tunicamycin $(0.3 \mu \mathrm{g} / \mathrm{ml})$, and $37^{\circ} \mathrm{C}$. Interestingly, VopE mediated lethality was observed in W303$1 \mathrm{~A}$ in the presence of the stressors (caffeine, $\mathrm{NaCl}$, sorbitol, and tunicamycin; Figure 6A). To further examine the cellular targets of VopE lacking MTS variant (VopE ${ }^{\Delta \mathrm{MTS}}$ ), BY4741$\mathrm{VopE}^{\triangle \mathrm{MTS}}$ recombinant strain was grown in the presence of various stressors. We observed an increase in lethality of $\mathrm{VopE}^{\triangle \mathrm{MTS}}$ only in the presence of caffeine and tunicamycin (Figure 6B). Since yeast growth in the presence of caffeine and tunicamycin mediated stress condition require functional CWI and UPR signaling pathways respectively (Parsons et al., 2004; Kuranda et al., 2006), these results suggested that VopE and its mutant form (VopE ${ }^{\triangle \mathrm{MTS}}$ ) strongly perturbed the activation of CWI and UPR pathways. VopE also caused yeast growth failure in osmotic conditions reflecting attenuation of high osmolarity glycerol MAPK pathway. It may be noted that YopE, the Yersinia homolog of VopE, also targets CWI pathway (Kramer et al., 2007).

There are six MAPK cascades have been characterized in yeast mediating response to different stimuli namely (i) pheromone responsive pathway; (ii) filamentous growth pathway; (iii) highosmolarity glycerol pathway; (iv) STE vegetative pathway; (v) nutrient starvation pathway; (vi) CWI pathway (Chen and Thorner, 2007; Arias et al., 2011). In order to identify the specific MAP kinase pathways which are majorly attenuated by VopE and its truncated form $\left(V_{o p E}{ }^{\triangle M T S}\right.$ ), we performed lacZ-reporter 
A

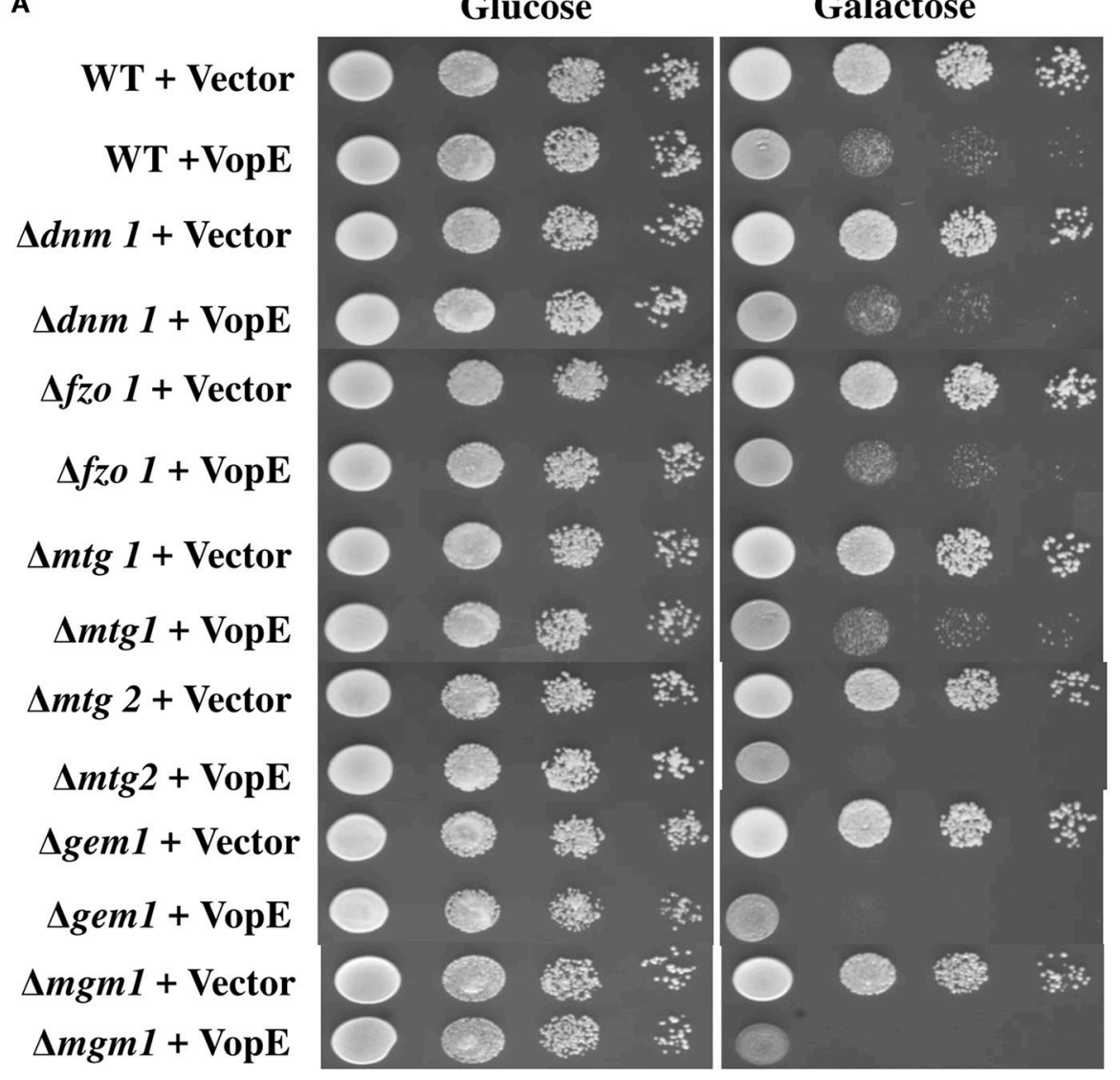

B

Glucose

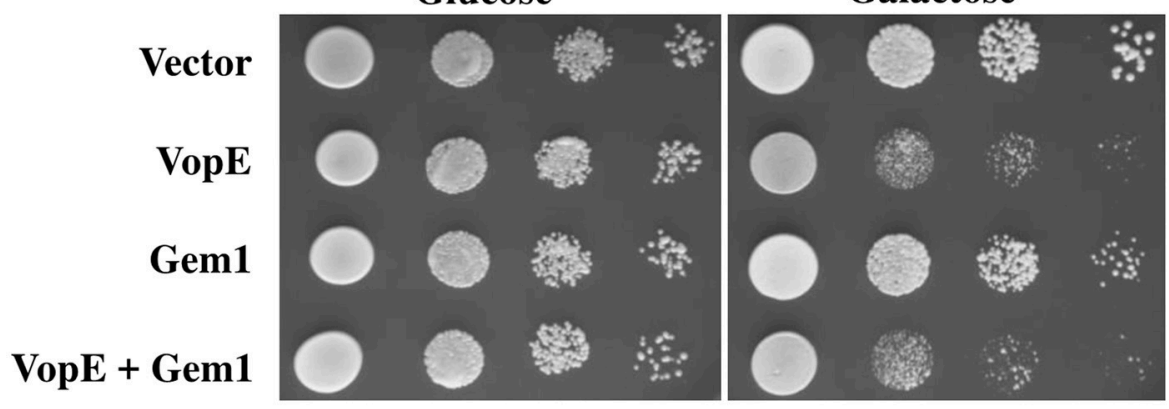

FIGURE 5 | Deletion or Over expression of Gem1 does not rescue yeast growth inhibition. 10-fold serial dilutions of (A) indicated BY4741 deletion strains containing eitheir pESCLEU or VopE (B) BY4741 transformants carrying either Gem1 alone or Gem1 and VopE, were subjected to spotting on selective solid media with glucose or galactose.

assay with recombinant yeast strains harboring VopE and $\mathrm{VopE}^{\Delta \mathrm{MTS}}$ along with lacZ-reporter plasmids of various MAPK signaling pathways (CWI, HOG, Pheromone) and ER stress pathways (UPR). The results clearly showed that VopE inhibited the activation of (i) pheromone signaling pathway $(32 \%$ inhibition); (ii) CWI pathway (73\% inhibition); (iii) unfolded protein response pathway (UPR; 70\% inhibition). Interestingly, $\mathrm{VopE}^{\triangle \mathrm{MTS}}$ also significantly suppressed the activation of UPR and CWI pathways (Figures 7A-C).
Targeting multiple MAPK pathways has been reported for other effector proteins e.g., YopJ, HopX1 (Yoon et al., 2003; Salomon et al., 2012). It may be noted that no inhibition of lacZ reporter activity corresponding to HOG pathway was observed (Figure 7D), but toxicity of VopE was observed in the presence of $\mathrm{NaCl}$ and sorbitol (Figure 6A). Such discrepancy has also been reported earlier, caffeine increases the toxicity of XopE2, a T3SS effector of Xanthomonas campestris, but no inhibition of lacZ reporter activity corresponding to CWI 
A

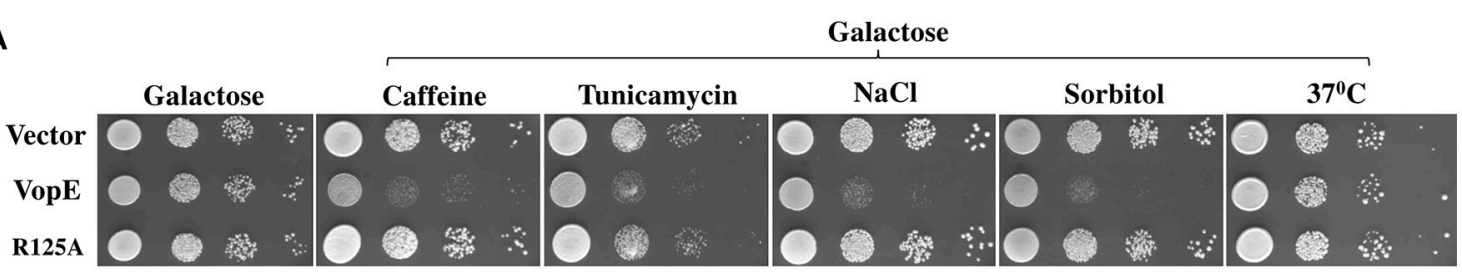

B
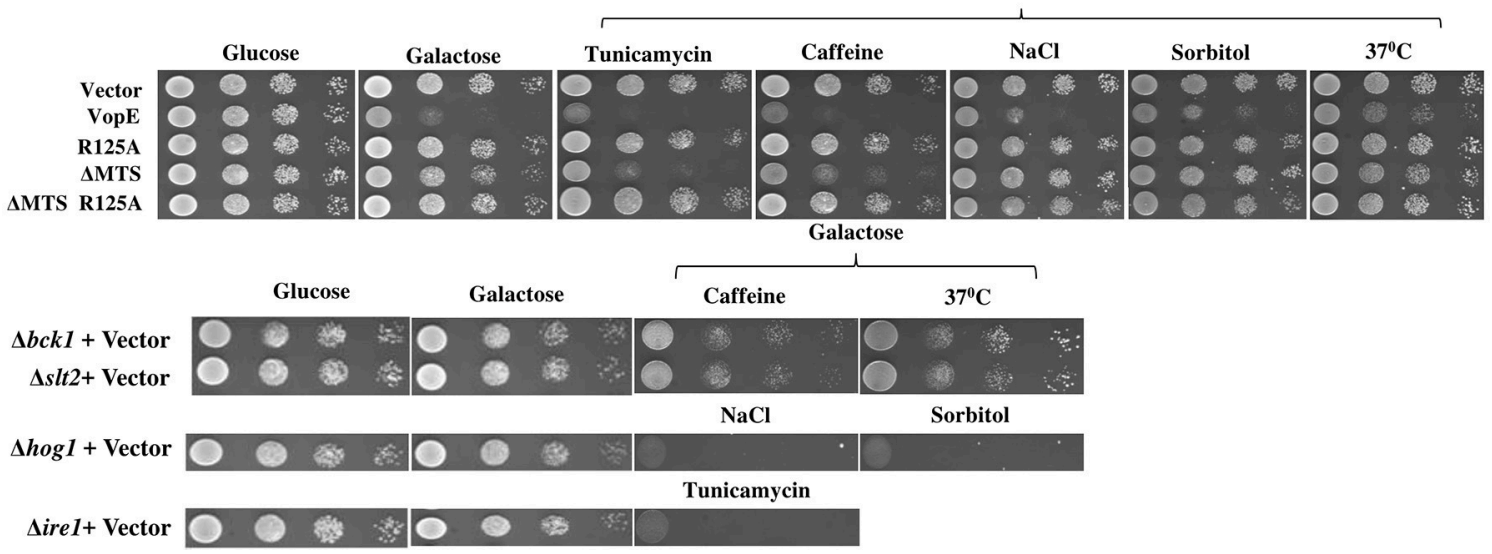

FIGURE 6 | Enhanced yeast toxicity under various stress conditions caused by VopE and VopE ${ }^{\Delta M T S}$. Yeast growth inhibition phenotypes of (A) W303-1A transformants carrying either VopE or VopE ${ }^{R 125 A}$ (B) BY4741 transformants carrying VopE or its derivatives were examined by spotting on solid selection media containing galactose (inducing) plate without or with stressors. pESCLEU used as cloning vector. Stressors used in this experiment were as follows: Caffeine ( $3 \mathrm{mM}$ ), Tunicamycin $(0.3 \mu \mathrm{g} / \mathrm{ml}), \mathrm{NaCl}(0.5 \mathrm{M})$, Sorbitol $(1 \mathrm{M}), 37^{\circ} \mathrm{C}$. Corresponding stressor sensitized BY4741 deletion strains $(\Delta b c k 1, \Delta s / t 2, \Delta h o g 1, \Delta$ ire 1$)$ were also spotted. Each experiment was repeated three times with similar results.

pathway in the presence of caffeine was observed (Bosis et al., 2011).

\section{VopE ${ }^{\Delta M T S}$ Showed Enhanced Toxicity in Yeast Deletion Mutants of CWI Pathway}

To test whether yeast MAPK pathway components modulate the toxicity, we transformed VopE and $\mathrm{VopE}^{\Delta \mathrm{MTS}}$ in yeast strains deleted for MAPK components of different signaling pathways namely CWI $(\Delta s l t 2)$, High osmolarity glycerol ( $\Delta$ hog1), Pheromone $(\Delta k s s 1)$, and sporulation $(\Delta s m k 1)$, and examined their growth under galactose inducing conditions. Of these, slt2 deletion strain expressing $\mathrm{VopE}^{\Delta \mathrm{MTS}}$ showed increased yeast growth inhibition than wild type (Figure $\mathbf{8 A}$, Figure S2).

The CWI pathway maintains cell wall integrity and gets activated in the presence of diverse arrays of external stimuli such as heat stress, mating pheromones, oxidative stress, $\mathrm{pH}$ stress, cell wall mutations, cell wall stressors, and endoplasmic reticulum stress all of which are known to cause cell wall stress (Levin, 2005; Arias et al., 2011). We further examined the effect of VopE and its truncated version on various yeast deletion mutants of CWI pathway. Accordingly, VopE and VopE ${ }^{\Delta \mathrm{MTS}}$ were transformed into yeast deletion mutants ( $\Delta b c k 1, \Delta m k k 1$, $\Delta m k k 2, \Delta r l m 1, \Delta k d x 1)$ and the recombinant yeast strains were examined by spotting on solid agar plate. Unlike VopE, $\Delta b c k 1$ and $\Delta$ slt2 mutants expressing $\operatorname{VopE}^{\Delta \mathrm{MTS}}$ exhibit increased yeast growth inhibition as compared to wild type strain (Figure $\mathbf{8 A}$,
Figure S2). An increased toxicity in absence of $b c k 1$ and slt2 further indicates that $\mathrm{VopE}$ and $\mathrm{VopE}^{\triangle \mathrm{MTS}}$ may activate a cellular response opposing the function of Bck1p and Slt2p. Such cases of hypersensitivity have been recorded with other effectors (e.g., OspF, XopE2, CBU1676, and CBU0885) as well (Kramer et al., 2007; Bosis et al., 2011; Lifshitz et al., 2014). It should be noted that lethality of VopE and $\operatorname{VopE}^{\Delta M T S}$ was observed to be enhanced by tunicamycin, an UPR pathway activator. If VopE targets UPR pathway, then it should remain non-lethal in yeast deletion mutant of UPR pathway $(\Delta$ ire 1$)$. Instead, we observed maintenance of toxicity which further emphasizes that VopE does not target UPR pathway (Figure S3). It has been pointed out by Sessa and colleagues that tunicamycin is highly toxic to mutants with cell wall defects (Salomon et al., 2012). It is therefore possible toxicity of effectors targeting CWI such as VopE is exacerbated in the presence of tunicamycin.

Next, we wanted to investigate whether VopE mediated growth inhibition was due to initiation of apoptosis. Thus, we transformed VopE in yeast mutant $\Delta y c a 1$, carrying a deletion in the metacaspase gene, YCA1 and subsequently examined the viability of recombinant $\triangle y c a 1$ strain by solid agar spotting assay. If VopE targets YCA1, $\Delta y c a 1$ strain should remain viable in the presence of VopE. But we observed VopE maintained its lethality in YCA1 deleted strain which is comparable to wild type strain background (Figure 8B). These observations further reinforce that VopE and VopE ${ }^{\Delta M T S}$ 

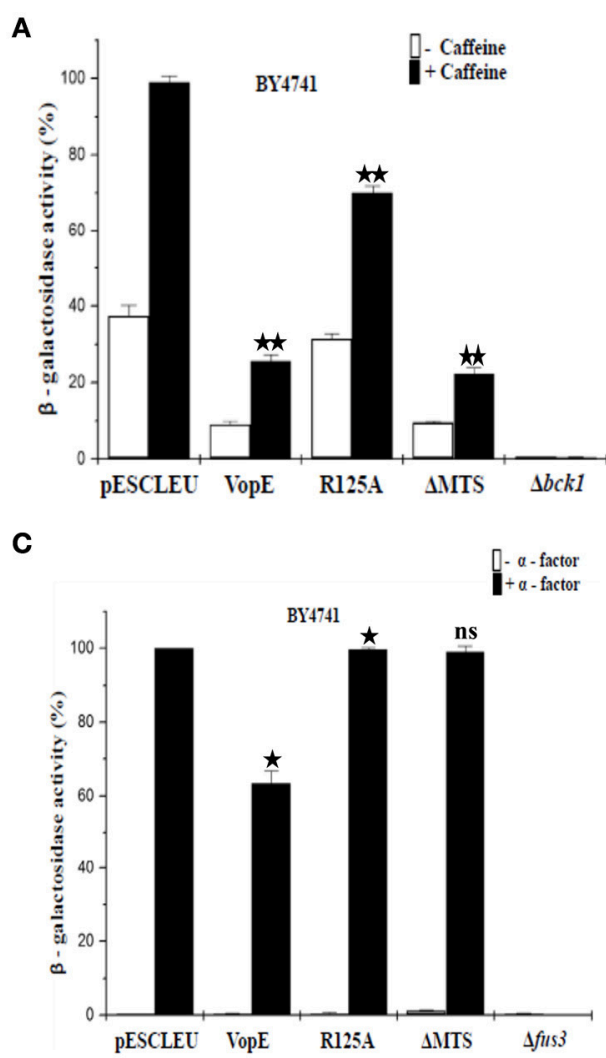

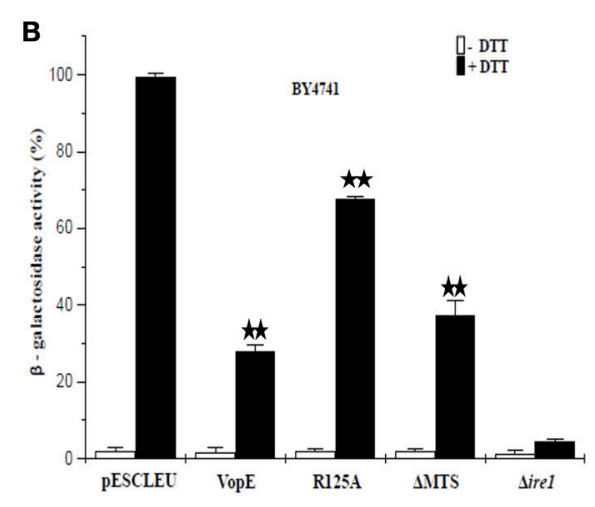

。

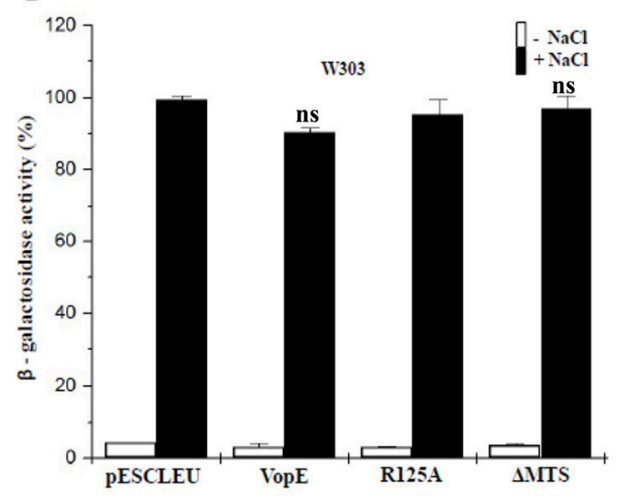

FIGURE 7 | Effect of VopE and VopE ${ }^{\Delta M T S}$ on yeast MAPK pathways and ER stress response. Under inducing conditions, (A) BY4741 yeast strains harboring $2 \mathrm{X}-\mathrm{RIm} 1$ regulated lacZ reporter plasmid and VopE or its derivatives were treated with $3 \mathrm{mM}$ caffeine for $4 \mathrm{~h}$. VopE and VopE ${ }^{\Delta M T S}$ significantly affect the activation of CWI-MAPK pathway. (B) Unfolded protein response was examined by incubating BY4741 transformants carrying UPRE regulated lacZ reporter plasmid and VopE or its derivatives in presence of $2 \mathrm{mM}$ DTT for $4 \mathrm{~h}$. VopE or VopE ${ }^{\Delta M T S}$ greatly hampered activation of UPR response. (C) Activation of $\mathrm{P}_{\mathrm{FUS1}}$-regulated lac $Z$ reporter was also monitored for BY4741 transformants carrying reporter plasmid and VopE or its derivatives in response to $5 \mu \mathrm{M} \alpha$-factor for $2 \mathrm{~h}$. Reduced activation of pheromone MAPK pathway has been observed in the presence of VopE. (D) For HOG-MAPK pathway, W303-1A strains containing $8 \times$ CRE-regulated lacZ reporter and VopE or its derivatives were incubated in the presence of $\mathrm{NaCl}(0.5 \mathrm{M})$ for $1 \mathrm{~h}$. Activation of reporter activity was not effected. Error bar depict the standard deviation from mean of three independent clones. All experiments were repeated three times with similar results. For VopE and VopE ${ }^{\Delta M T S}$, an asterisk(s) indicates a statistically significant difference in mean values as compared to pESCLEU. For VopE ${ }^{R 125 A}$, an asterisk(s) indicates a statistically significant difference in mean values as compared to $\operatorname{VopE}\left({ }^{\star} p<0.05 ;{ }^{\star \star} p<0.001\right.$; ns-not significant; unpaired, two tailed student's $t$-test).

interact with the components of cell wall maintenance related pathways.

\section{Co-Expression of VopE ${ }^{\Delta M T S}$ Partially Ameliorates the Lethal Effect of VopX in Yeast}

Co-expression of two effectors in yeast model has proven valuable in identification of suppressor function of certain effectors over other. Previously, it has been shown that $L$. pneumophila effectors, SidD, and SidJ were able to counteract the activity of SidM and SdeA respectively (Tan and Luo, 2011; Havey and Roy, 2015). We investigated the outcome of co-expression of $\mathrm{VopE}^{\Delta \mathrm{MTS}}$ with another $V$. cholerae effector VopX targeting similar cellular pathway, the CWI pathway in yeast (Alam et al., 2011; Seward et al., 2015). The dual expression constructs (Table 1) were transformed to $S$. cerevisiae strain BY4741. The recombinant yeast strains were subjected to solid agar spotting under galactose inducing condition. We observed a partial suppression of VopX mediated toxicity in dual expression condition by $\operatorname{VopE}^{\Delta \mathrm{MTS}}$ only (Figure 9). To further confirm the specificity, we co-expressed the functionally inert variant of $\mathrm{VopE}^{\triangle \mathrm{MTS}}$ harboring the substitution of catalytic arginine at position 125 with alanine $\left(\operatorname{VopE}^{\triangle \mathrm{MTS}} \mathrm{R} 125 \mathrm{~A}\right)$ along with VopX. We observed that VopE ${ }^{\Delta \text { MTS R125A }}$ did not inhibit VopX mediated toxicity further supporting the hypothesis that $\mathrm{VopE}^{\Delta \mathrm{MTS}}$ mediates suppression of VopX toxicity (Figure 9).

To summarize, the present work unfolds many additional features on functional aspects of VopE by exploiting yeast model system. These are as follows: (i) identification of several critical residues in GAP domain and N-terminal region of VopE conferring lethality in yeast system; (ii) VopE variant lacking mitochondrial localization signal possesses partial lethality; (iii) screening of yeast deletion library against VopE and its derivative $\operatorname{VopE}^{\Delta \mathrm{MTS}}$ results in the identification of hypersensitive strains; (iv) VopE and VopE $E^{\Delta M T S}$ 


\section{A}

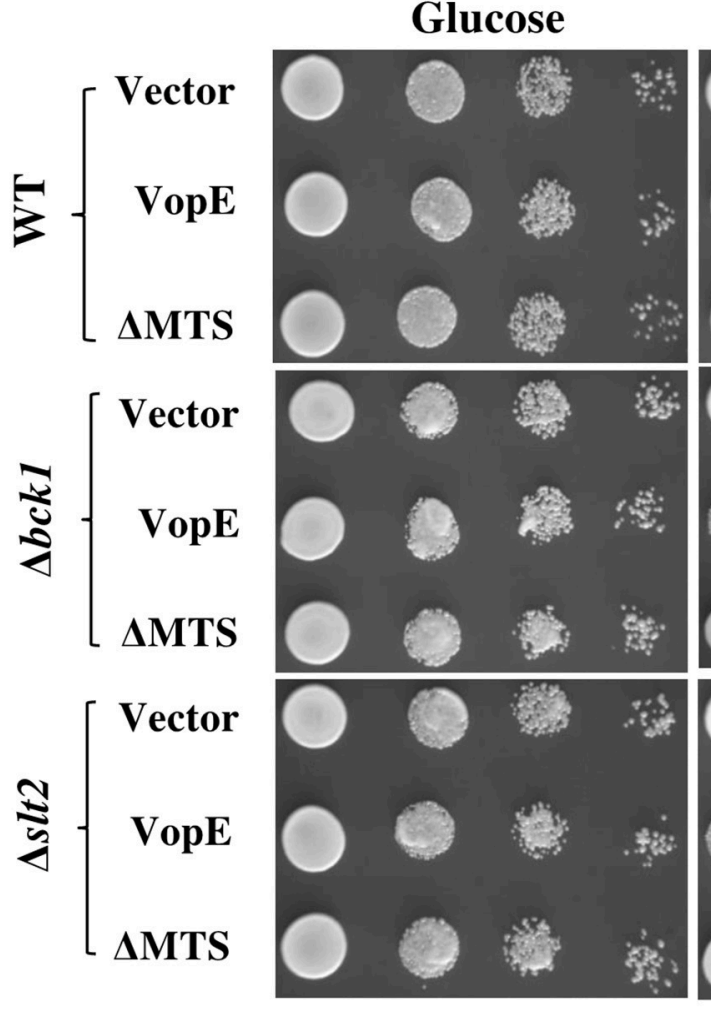

B

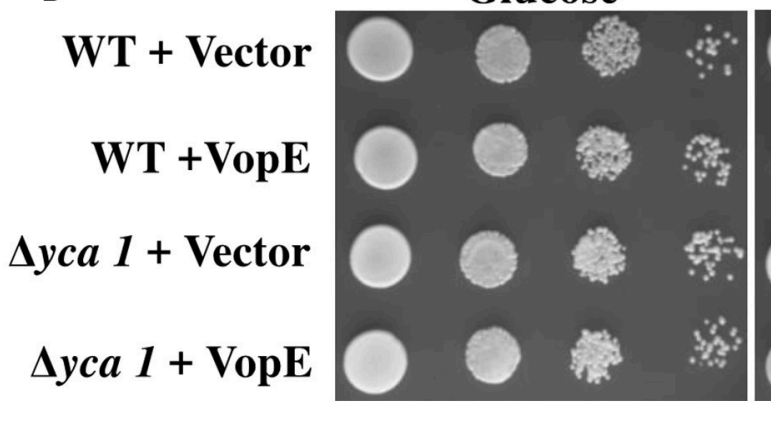

Galactose
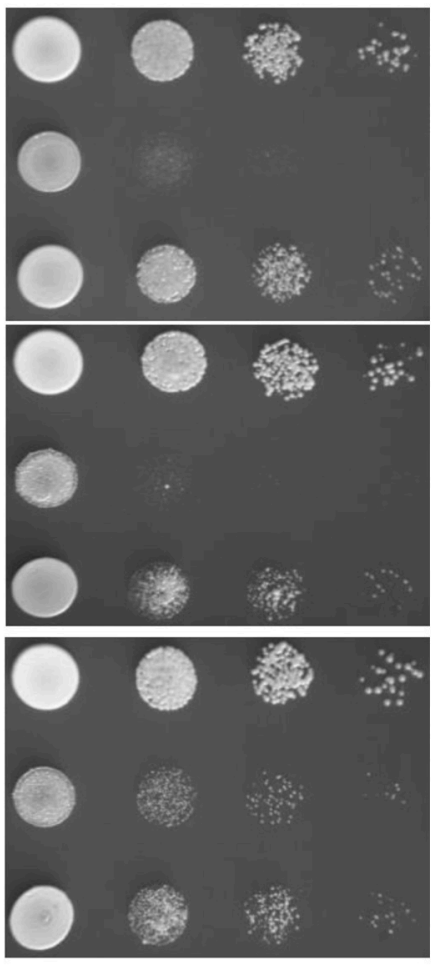

Galactose

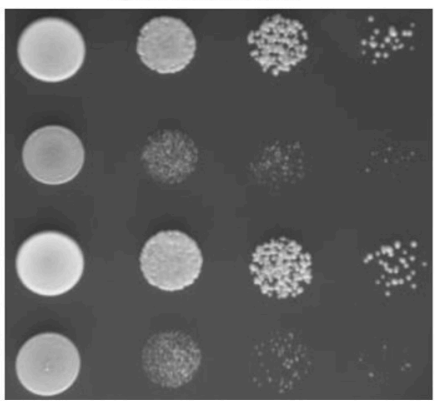

FIGURE 8 | Examination of VopE effect on CWI defective and metacaspase mutants. (A) BY4741 $\Delta b c k 1$ and BY4741 $\Delta s / t 2$ yeast deletion mutant strains showed increased yeast growth inhibition phenotype toward VopE ${ }^{\Delta M T S}$. (B) Over expression of VopE maintains toxicity in BY4741 $\Delta y c a 1$ strain. All transformants were examined under solid selection media containing glucose or galactose. pESCLEU used as cloning vector.

modulates CWI-MAPK pathway in yeast; (v) co-expression of $\mathrm{VopE}^{\Delta \mathrm{MTS}}$ and VopX causes functional perturbation of the latter.

\section{DISCUSSION}

In this study the budding yeast has been exploited as a model organism for functional exploration of VopE, a T3SS effector protein of $V$. cholerae. Previously, yeast has been used as a model organism to study the activity of several other $V$. cholerae T3SS effector proteins (Tripathi et al., 2010, 2013; Bankapalli et al., 2015; Seward et al., 2015).
It is now evident that one important host organelle targeted by several pathogens is the mitochondria (Jiang et al., 2012). Usually, proteins targeted to the mitochondria harbor specific signal sequence known as mitochondrial targeting signal (MTS) at the N-termini contributing to their import into mitochondria. Site-directed mutagenesis of MTS reveals the identification of critical residue (s) involved in the mitochondrial transportation of certain effectors (e.g., Map, EspF) (Nagai et al., 2005; Papatheodorou et al., 2006). In case of some proteins, PorB (Neisseria gonorrhoeae), and VacA (Helicobacter pylori), removal of $\mathrm{N}$ and $\mathrm{C}$-termini did not affect their mitochondrial localization, indicating that signals are not restricted at the termini only (Kozjak-Pavlovic et al., 2009; Foo et al., 2010; 


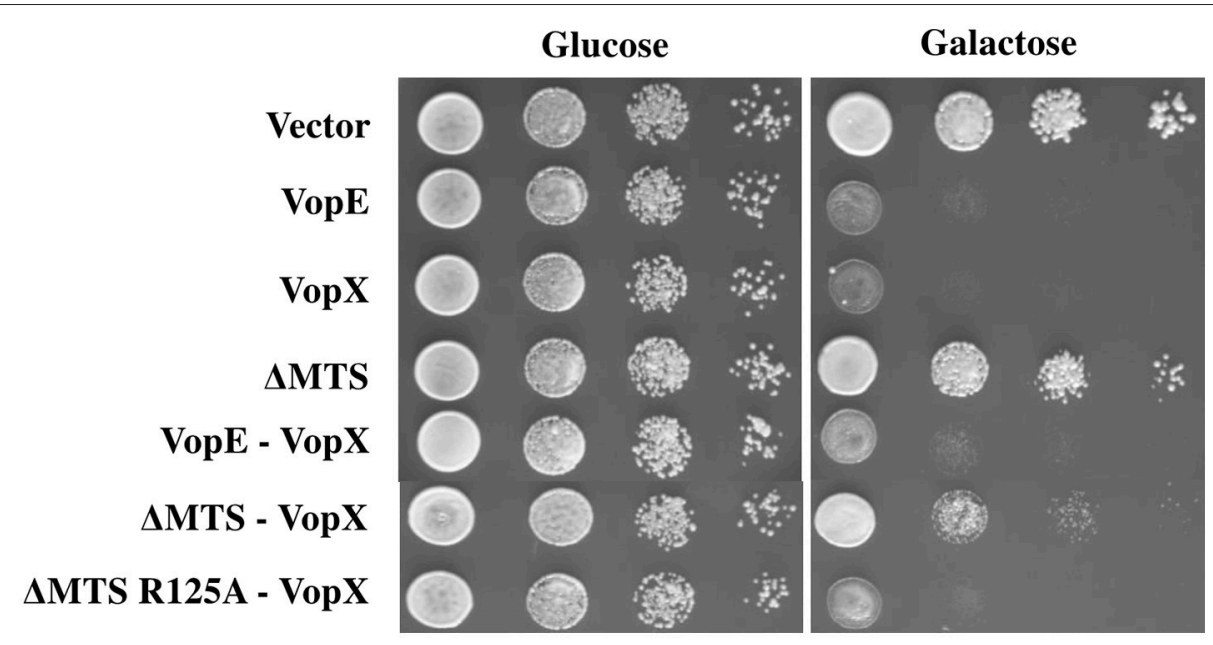

FIGURE 9 | Expression of VopE ${ }^{\Delta M T S}$ suppresses yeast growth inhibition of VopX. (A) BY4741 transformants carrying VopX and VopE ${ }^{\Delta M T S}$, VopX and $V_{0 p} \triangle$ MTS R125A, or VopX and VopE were spotted on glucose and galactose plates. pESCLEU used as cloning vector for dual expression, where VopX and VopE variants cloned under GAL10 and GAL1 promoters, respectively.

Jiang et al., 2012). Like many other mitochondria targeted effectors, localization of VopE is also dependent on the predicted mitochondrial-targeting sequence spanning 23 amino acids at the N-terminus. Deletion of MTS composed of 23 amino acids $\left(V_{o p E^{\Delta M T S}}\right)$ or substitution of leucine with glutamate at position 4 in the MTS (VopE ${ }^{\mathrm{L} 4 \mathrm{E}}$ ) abolishes the localization of VopE in mitochondria. Unlike many mitochondria targeted effectors, VopE does not promote the death of host cells. Functionally, it modulates innate immune signaling through mitochondrial dynamics (Suzuki et al., 2014).

Effectors having localization signals of various cellular compartments (e.g., Map, ExoS, YopE etc.) still maintain toxicity even after removal of the signal (Zhang and Barbieri, 2005; Papatheodorou et al., 2006; Isaksson et al., 2009; Geissler et al., 2010). Interestingly, one mitochondrial targeted effector of enteropathogenic E. coli known as Map is found to be more toxic after removal of MTS in yeast model system (Papatheodorou et al., 2006). Keeping this in mind, we wanted to investigate and garner additional insight on the functionality of VopE by exploiting yeast model system. Our data clearly indicated that ectopic expression of VopE and $\mathrm{VopE}^{\Delta \mathrm{MTS}}$ caused toxicity to yeast cells.

VopE is a member of bacterial GAP family protein. Structural and functional analysis of certain bacterial GAPs clearly establishes a communication network between several conserved residues imparting the GAP function. By employing in silico analysis followed by site-directed mutagenesis and functional evaluation in yeast model system, we have identified several residues other than R125 contributing to the lethal function of VopE. It should be noted that natural sensitivity of BY4741 to VopE mediated toxicity further aid in the identification of critical residues in VopE.

There is now a large body of evidence on strategies used by pathogens to control host signaling pathways especially kinase signaling pathways (Krachler et al., 2011). Various kinase signaling pathways such as nuclear factor-kB (NF-kB), mitogenactivated protein kinase (MAPK), phosphatidylinositol 3-kinase (PI3K), and p21-activated kinase (PAK) are hijacked by different phylogenitically related and unrelated pathogens (Krachler et al., 2011). Interestingly, T3SS effectors of some of these pathogens (e.g., YopJ, VopA, OspF) have been shown to inhibit MAPK kinase signaling pathways in yeast model system as well (Yoon et al., 2003; Trosky et al., 2004; Kramer et al., 2007). With the help of stressors, $\beta$-galactosidase assay and yeast deletion strains, we have revealed that VopE and its variant VopE ${ }^{\Delta \mathrm{MTS}}$ modulate CWI-MAPK pathway in yeast model system, but the mechanism is not clear. Yeast two-hybrid analysis of $\mathrm{VopE}^{\Delta \mathrm{MTS}}$ against prenylation defective GTPases (Rho1, Rho1 ${ }^{\mathrm{Q} 68 \mathrm{H}}$, Rho2, Rho2 $\left.{ }^{\mathrm{Q} 65 \mathrm{H}}, \mathrm{CDC} 42, \mathrm{CDC} 42^{\mathrm{Q} 61 \mathrm{~L}}\right)$ failed to detect any possible interaction (data not shown).

Being the principal signaling pathway maintaining the architecture of yeast cell wall, the structural and functional aspects of CWI MAPK pathway have been studied in great detail (Levin, 2005). There is now a growing list of diverse effector proteins (e.g., OspF of Shigella; Icm/Dot effectors of C. burnetti; VopX of V. cholerae; YopE of Y. pestis) perturbing the function of CWI-MAPK pathway in yeast model system (Kramer et al., 2007; Lifshitz et al., 2014; Seward et al., 2015). As evidenced, T3SS effectors of different bacteria target and alter the function of various components of CWI pathway. While OspF inhibits the phosphorylation of Slt2, the terminal MAP Kinase of CWI pathway (Kramer et al., 2007), VopX modulates Rlm1 function and Rlm1 mediated downstream genes expression by interacting components at the top of MAPK cascade (Alam et al., 2011; Seward et al., 2015). Interestingly, CBU0388, CBU0885, and CBU1676, effectors of C. burnetti interact differentially with the various MAP Kinases of CWI pathway. While yeast deletion mutants $(\Delta b c k 1$ and $\Delta m p k 1)$ of CWI pathway exhibit hypersensitivity upon expression of CBU1676 and CBU0885, the same mutants result complete suppression of CBU0388 
lethality (Lifshitz et al., 2014). Our observation of VopE mediated functional modulation of CWI-MAPK pathway will extend the growing list of bacterial effectors targeting this important cellular pathway in yeast. Finally, our co-expression of two effectors interfering CWI-MAPK, VopE ${ }^{\triangle \mathrm{MTS}}$ and VopX, exhibited the suppression of lethality of the latter in the yeast model.

As demonstrated previously, VopE targets Miro GTPase and causes functional modulation of the innate immune system (Suzuki et al., 2014). The Miro ortholog in the budding yeast is Gem1p (Frederick et al., 2004). If VopE lethality in yeast is linked to Gemlp, then VopE should not exert toxicity either in BY4741 $\Delta$ gem 1 or its toxicity should be mitigated upon over expression of gene encoding Gem1p. Our data clearly demonstrated that VopE maintained its lethal property in BY4741 $\Delta$ gem 1 as well as BY4741 harboring Gem1p overexpression construct, thereby indicating lethality of VopE is not mediated by Gem1p. Interestingly, substitution of critical arginine finger residue at position 125 (R125) by alanine (R125A) conferred non-functionality in VopE and $\mathrm{VopE}^{\Delta \mathrm{MTS}}$ further corroborated that GAP function is required for the lethality of these proteins in yeast system. Currently, the targeted GTPase(s) of VopE and its variant in yeast model system is not known. This warrants further investigation.

\section{AUTHOR CONTRIBUTIONS}

SR conceived the idea. SR and LB designed the experiments. LB carried out all the experiments. RM repeated the experiments. SR

\section{REFERENCES}

Alam, A., Miller, K. A., Chaand, M., Butler, J. S., and Dziejman, M. (2011). Identification of Vibrio cholerae type III secretion system effector proteins. Infect. Immun. 79, 1728-1740. doi: 10.1128/IAI.01194-10

Antic, I., Biancucci, M., and Satchell, K. J. (2014). Cytotoxicity of the Vibrio vulnificus MARTX toxin Effector DUF5 is linked to the C2A subdomain. Proteins 82, 2643-2656. doi: 10.1002/prot.24628

Arias, P., Diez-Muniz, S., Garcia, R., Nombela, C., Rodriguez-Pena, J. M., and Arroyo, J. (2011). Genome-wide survey of yeast mutations leading to activation of the yeast cell integrity MAPK pathway: novel insights into diverse MAPK outcomes. BMC Genomics 12:390. doi: 10.1186/1471-2164-12-390

Auesukaree, C., Damnernsawad, A., Kruatrachue, M., Pokethitiyook, P., Boonchird, C., and Kaneko, Y. (2009). Genome-wide identification of genes involved in tolerance to various environmental stresses in Saccharomyces cerevisiae. J. Appl. Genet. 50, 301-310. doi: 10.1007/BF03195688

Bankapalli, L. K., Mishra, R. C., Singh, B., and Raychaudhuri, S. (2015). Identification of critical amino acids conferring lethality in VopK, a Type III effector protein of Vibrio cholerae: lessons from yeast model system. PLoS ONE 10:e0141038. doi: 10.1371/journal.pone.0141038

Bénit, P., Schiff, M., Sainsard-Chanet, A., and Rustin, P. (2010). Genetic background influences mitochondrial function: modeling mitochondrial disease for therapeutic development. Trends Mol. Med. 16, 210-217. doi: 10.1016/j.molmed.2010.03.001

Bosis, E., Salomon, D., and Sessa, G. (2011). A simple yeast-based strategy to identify host cellular processes targeted by bacterial effector proteins. PLOS ONE 6:e27698. doi: 10.1371/journal.pone.0027698

Busch, C., and Aktories, K. (2000). Microbial toxins and the glucosylation of Rho family GTPases. Curr. Opin. Struct. Biol. 10, 528-535. doi: 10.1016/S0959-440X(00)00126-3 wrote the manuscript. All the authors gave their editorial input and approved the final manuscript.

\section{FUNDING}

This work was supported by the CSIR program on supra institutional project (SIP-BSC0210E). LB and RM received research fellowships from Department of Biotechnology (DBT, India) and CSIR project (UNSEEN-CSIR) respectively. Funder has no role in the design of study, analysis and interpretation of data and in writing the manuscript.

\section{ACKNOWLEDGMENTS}

We gratefully acknowledge Prof. Guido Sessa, Tel Aviv University, Israel for the generous gift of all lacZ reporter plasmids used in this study. We also thank Drs. K. Ganesan and Deepak Sharma, CSIR-Institute of Microbial Technology for giving us yeast deletion strains and pRS413 plasmid respectively. We thank Dr. Rukhsana Chowdhury, CSIR-Indian Institute of Chemical Biology for editorial input.

\section{SUPPLEMENTARY MATERIAL}

The Supplementary Material for this article can be found online at: http://journal.frontiersin.org/article/10.3389/fcimb. 2017.00082/full\#supplementary-material
Chen, R. E., and Thorner, J. (2007). Function and regulation in mapk signaling pathways: lessons learned from the yeast Saccharomyces cerevisiae. Biochim. Biophys. Acta 1773, 1311-1340. doi: 10.1016/j.bbamcr.2007.05.003

Curak, J., Rohde, J., and Stagljar, I. (2009). Yeast as a tool to study bacterial effectors. Curr. Opin. Microbiol. 12, 18-23. doi: 10.1016/j.mib.2008.11.004

Dean, P. (2011). Functional domains and motifs of bacterial type III effector proteins and their roles in infection. FEMS Microbiol. Rev. 35, 1100-1125. doi: 10.1111/j.1574-6976.2011.00271.x

Dziejman, M., Serruto, D., Tam, V. C., Sturtevant, D., Diraphat, P., Faruque, S. M., et al. (2005). Genomic characterization of non-O1, non-O139 Vibrio cholerae reveals genes for a type III secretion system. Proc. Natl. Acad. Sci. U.S.A. 102, 3465-3470. doi: 10.1073/pnas.0409918102

Foo, J. H., Culvenor, J. G., Ferrero, R. L., Kwok, T., Lithgow, T., and Gabriel, K. (2010). Both the p33 and p55 subunits of the Helicobacter pylori VacA toxin are targeted to mammalian mitochondria. J. Mol. Biol. 401, 792-798. doi: $10.1016 /$ j.jmb.2010.06.065

Frederick, R. L., McCaffery, J. M., Cummingham, K. W., Okamoto, K., and Shaw, J. M. (2004). Yeast Miro GTPase, Gem1p, regulates mitochondrial morphology via a novel Pathway. J. Cell Biol. 167, 87-98. doi: 10.1083/jcb.200405100

Frederick, R. L., and Shaw, J. M. (2007). Moving mitochondria: establishing distribution of an essential organelle. Traffic 8, 1668-1675. doi: $10.1111 / j .1600-0854.2007 .00644 . x$

Galkin, V. E., Orlova, A., Vanloock, M. S., Zhou, D., Galan, J. E., and Egelman, E. H. (2002). The bacterial protein SipA polymerizes G-actin and mimics muscle nebulin. Nat. Struct. Biol. 9, 518-521. doi: 10.1038/nsb811

Geissler, B., Tungekar, R., and Satchell, K. J. (2010). Identification of a conserved membrane localization domain within numerous large bacterial protein toxins. Proc. Natl. Acad. Sci.U.S.A. 107, 5581-5586. doi: 10.1073/pnas.0908700107

Gregg, C., Kyryakov, P., and Titorenko, V. I. (2009). Purification of mitochondria from yeast cells. J. Vis. Exp. 30:1417. doi: 10.3791/1417 
Gustin, M. C., Albertyn, J., Alexander, M., and Davenport, K. (1998). MAP kinase pathways in the yeast Saccharomyces cerevisiae. Microbiol. Mol. Biol. Rev. 62, $1264-1300$.

Havey, J. C., and Roy, C. R. (2015). Toxicity and SidJ-Mediated suppression of toxicity require distinct regions in the SidE family of Legionella pneumophila Effectors. Infect. Immun. 83, 3506-3514. doi: 10.1128/IAI.00497-15

Hohmann, S. (2002). Osmotic stress signaling and osmoadaptation in yeasts. Microbiol. Mol. Biol. Rev. 66, 300-372. doi: 10.1128/MMBR.66.2.300-372.2002

Hunter, T., and Plowman, G. D. (1997). The protein kinases of budding yeast: six score and more. Trends Biochem. Sci. 22, 18-22. doi: 10.1016/S0968-0004(96)10068-2

Isaksson, E. L., Aili, M., Fahlgren, A., Carlsson, S. E., Rosgvist, R., and Wolf-Watz, H. (2009). The membrane localization domain is required for intracellular localization and auto regulation of YopE in Yersinia pseudotuberculosis. Infect. Immun. 77, 4740-4749. doi: 10.1128/IAI.00333-09

Jiang, J. H., Tong, J., and Gabriel, K. (2012). Hijacking mitochondria: bacterial toxins that modulate mitochondrial function. IUBMB Life 64, 397-401. doi: $10.1002 /$ iub.1021

Kippert, F. (1995). A rapid permeabilization procedure for accurate quantitative determination of beta - galactosidase activity in yeast cells. FEMS Microbiol. Lett. 128, 201-206.

Kozjak-Pavlovic, V., Dian-Lothrup, E. A., Meinecke, M., Kepp, O., Ross, K., Rajalingam, K., et al. (2009). Bacterial porin disrupts mitochondrial membrane potential and sensitizes host cells to apoptosis. PLoS Pathog. 5:e1000629. doi: 10.1371/journal.ppat.1000629

Krachler, A. M., Woolery, A. R., and Orth, K. (2011). Manipulation of kinase signaling by bacterial pathogens. J. Cell Biol. 195, 1083-1092. doi: $10.1083 /$ jcb.201107132

Kramer, R. W., Slagowski, N. L., Eze, N. A., Giddings, K. S., Morrison, M. F., Siggers, K. A., et. al. (2007). Yeast functional genomic screens lead to identification of a role for bacterial effector in innate immunity regulation. PLoS Pathog. 3:e21. doi: 10.1371/journal.ppat.0030021

Kumar, Y., Cocchiaro, J., and Valdivia, R. H. (2006). The obligate intracellular pathogen Chlamydia trachomatis targets host lipid droplets. Curr. Biol. 16, 1646-1651. doi: 10.1016/j.cub.2006.06.060

Kuranda, K., Leberre, V., Sokol, S., Palamarczyk, G., and Francois, J. (2006). Investigating the caffeine effects in the yeast Saccharomyces cerevisiae brings new insights into the connection between TOR, PKC and Ras/cAMP signalling pathways. Mol. Microbiol. 61, 1147-1166. doi: $10.1111 /$ j.1365-2958.2006.05300.x

Lesser, C. F., and Miller, S. I. (2001). Expression of microbial virulence proteins in Saccharomyces cerevisiae models mammalian infection. EMBO J. 20, 1840-1849. doi: $10.1093 / \mathrm{emboj} / 20.8 .1840$

Levin, D. E. (2005). Cell wall integrity signaling in Saccharomyces cerevisiae. Microbiol. Mol. Biol. Rev. 69, 262-291. doi: 10.1128/MMBR.69.2.262-291.2005

Lifshitz, Z., Burstein, D., Schwartz, K., Shuman, H. A., Pupko, T., and Segal, G. (2014). Identification of Novel Coxiella burnetii $\mathrm{Icm} /$ Dot effectors and genetic analysis of their involvement in modulating a mitogen-activated protein kinase pathway. Infect. Immun. 82, 3740-3752. doi: 10.1128/IAI.01729-14

Litvak, Y., and Selinger, Z. (2003). Bacterial mimics of eukaryotic GTPase-activating proteins (GAPs). Trends Biochem. Sci. 28, 628-631. doi: 10.1016/j.tibs.2003.10.001

Munkvold, K. R., Martin, M. E., Bronstein, P. A., and Collmer, A. (2008). A survey of the Pseudomonas syringae pv. tomato DC3000 type III secretion system effector repertoire reveals several effectors that are deleterious when expressed in Saccharomyces cerevisiae. Mol. Plant Microbe Interact. 21, 490-502. doi: 10.1094/MPMI-21-4-0490

Nagai, T., Abe, A., and Sasakawa, C. (2005). Targeting of enteropathogenic Escherichia coli EspF to host mitochondria is essential for bacterial pathogenesis: critical role of the 16th leucine residue in EspF. J. Biol. Chem. 280, 2998-3011. doi: 10.1074/jbc.M411550200

Otsuga, D., Keegan, B. R., Brisch, E., Thatcher, J. W., Hermann, G. J., Bleazard, W., et al. (1998). The Dynamin-related GTPase, Dnmlp, controls mitochondrial morphology in yeast. J. Cell Biol. 143, 333-349. doi: 10.1083/jcb.143.2.333

Papa, F. R., Zhang, C., Shokat, K., and Walter, P. (2003). Bypassing a kinase activity with an ATP-competitive drug. Science 302, 1533-1537. doi: $10.1126 /$ science. 1090031
Papatheodorou, P., Domanska, G., Oxle, M., Mathieu, J., Selchow, O., Kenny, B., et al. (2006). The enteropathogenic Escherichia coli (EPEC) map effector is imported into the mitochondrial matrix by the TOM/Hsp70 system and alters organelle morphology. Cell Microbiol. 8, 677-689. doi: 10.1111/j.1462-5822.2005.00660.x

Parsons, A. B., Brost, R. L., Ding, H., Li, Z., Zhang, C., Sheikh, B., et al. (2004). Integration of chemical-genetic and genetic interaction data links bioactive compounds to cellular target pathways. Nat. Biotechnol. 22, 62-69. doi: $10.1038 /$ nbt919

Pereira, C., Coutinho, I., Soares, J., Bessa, C., Leao, M., and Saraiva, L. (2012). New insights into cancer-related proteins provided by the yeast model. FEBS J. 279, 697-712. doi: 10.1111/j.1742-4658.2012.08477.x

Popa, C., Coll, N. S., Valls, M., and Sessa, G. (2016). Yeast as a heterologous model system to uncover Type III effector function. PLoS Pathog. 12:e1005360. doi: 10.1371/journal.ppat.1005360

Rodríguez-Escudero, I., Hardwidge, P. R., Nombela, C., Cid, V. J., Finlay, B. B. and Molina, M. (2005). Enteropathogenic Escherichia coli type III effectors alter cytoskeletal function and signaling in Saccharomyces cerevisiae. Microbiology 151, 2933-2945. doi: 10.1099/mic.0.28072-0

Rodríguez-Pachón, J. M., Martín, H., North, G., Rotger, R., Nombela, C., and Molina, M. (2002). A novel connection between the yeast Cdc42 GTPase and the Slt2-mediated cell Integrity pathway identified through the effect of secreted Salmonella GTPase modulators. J. Biol. Chem. 277, 27094-27102. doi: 10.1074/jbc.M201527200

Salomon, D., Bosis, E., Dar, D., Nachman, I., and Sessa, G. (2012). Expression of Pseudomonas syringae type III effectors in yeast under stress conditions reveals that HopX1 attenuates activation of the high osmolarity glycerol MAP kinase pathway. Microbiology 158, 2859-2869. doi: 10.1099/mic.0.062513-0

Salomon, D., Dar, D., Sreeramulu, S., and Sessa, G. (2011). Expression of Xanthomonas campestris pv. Vesicatoria type III effectors in yeast affects cell growth and viability. Mol. Plant Microbe Interact. 24, 305-314. doi: 10.1094/MPMI-09-10-0196

Salomon, D., Guo, Y., Kinch, N. L., Grishin, V. N., Gardner, H. K., and Orth, K. (2013). Effectors of animal and plant pathogens use a common domain to bind host Phosphoinositides. Nat. Commun. 4:2973. doi: 10.1038/ncomms3973

Sampath, V., Rekha, N., Srinivasan, N., and Sadhale, P. (2003). The Conserved and non-conserved regions of Rpb4 are involved in multiple phenotypes in Saccharomyces cerevisiae J. Biol. Chem. 278, 51566-51576. doi: 10.1074/jbc.M305863200

Seward, C. H., Manzella, A., Alam, A., Butler, J. S., and Dziejman, M. (2015). Using S. cerevisiae as a Model System to Investigate V. cholerae VopX-Host Cell protein interactions and phenotypes. Toxins 7, 4099-4110. doi: 10.3390/toxins7104099

Shaw, J. M., and Nunnari, J. (2002). Mitochondrial dynamics and division in budding yeast. Trends Cell Biol. 12, 178-184. doi: 10.1016/S0962-8924(01)02246-2

Shin, O. S., Tam, V. C., Suzuki, M., Ritchie, J. M., Bronson, R. T., Waldor, M. K., et al. (2011). Type III secretion is essential for the rapidly fatal diarrheal disease caused by non-O1, non-O139 Vibrio cholerae. MBio 2, e00106-e0111. doi: $10.1128 / \mathrm{mBio} .00106-11$

Siggers, K. A., and Lesser, C. F. (2008). The Yeast Saccharomyces cerevisiae: a versatile model system for the identification and characterization of bacterial virulence proteins. Cell Host Microbe. 4, 8-15. doi: 10.1016/j.chom.2008. 06.004

Sisko, J. L., Spaeth, K., Kumar, Y., and Valdivia, R. H. (2006). Multifunctional analysis of Chlamydia-specific genes in a yeast expression system. Mol. Microbiol. 60, 51-66. doi: 10.1111/j.1365-2958.2006.05074.x

Slagowski, N. L., Kramer, R. W., Morrison, M. F., LaBaer, J., and Lesser, C. F. (2008). A functional genomic yeast screen to identify pathogenic bacterial proteins. PLoS Pathog. 4:e9. doi: 10.1371/journal.ppat.0040009.

Stebbins, C. E., and Galan, J. E. (2000). Modulation of host signaling by a bacterial mimic: structure of the salmonella effector SptP bound to Rac1. Mol. Cell 6, 1449-1460. doi: 10.1016/S1097-2765(00)00141-6

Suzuki, M., Danilchanka, O., and Mekalanos, J. J. (2014). Vibrio cholerae T3SS effector VopE modulates mitochondrial dynamics and innate immune signaling by targeting Miro-GTPases. Cell Host Microbe. 16, 581-591. doi: 10.1016/j.chom.2014.09.015 
Tam, V. C., Serruto, D., Dziejman, M., Brieher, W., and Mekalanos, J. J. (2007). A type III secretion system in Vibrio cholerae translocates a formin/spire hybridlike actin nucleator to promote intestinal colonization. Cell Host Microbe. 1, 95-107. doi: 10.1016/j.chom.2007.03.005

Tam, V. C., Suzuki, M., Coughlin, M., Saslowsky, D., Biswas, K., Lencer, W. I., et al. (2010). Functional analysis of VopF activity required for colonization in Vibrio cholerae. MBio 1, 1-10. doi: 10.1128/mBio.00289-10

Tan, Y., and Luo, Z. Q. (2011). Legionella pneumophila SidD is a deAMPylase that modifies Rab1. Nature 475, 506-509. doi: 10.1038/nature10307

Tripathi, R., Kaithwas, V., Dureja, C., and Raychaudhuri, S. (2013). Alaninescanning mutagenesis of $\mathrm{WH} 2$ domains of VopF reveals residues important for conferring lethality in a Saccharomyces cerevisiae model. Gene 525, 116-123. doi: 10.1016/j.gene.2013.04.071

Tripathi, R., Singh, N. S., Dureja, C., Haldar, S., Mondal, A. K., and Raychaudhuri, S. (2010). VopF, a type III effector protein from a non-O1, non-O139 Vibrio cholera strain, demonstrates toxicity in a Saccharomyces cerevisiae model. J. Med. Microbiol. 59, 17-24. doi: 10.1099/jmm.0.012336-0

Trosky, J. E., Mukherjee, S., Burdette, D. L., Roberts, M., McCarter, L., Siegel, M. R., et al. (2004). Inhibition of MAPK signaling pathways by VopA from Vibrio parahaemolyticus. J. Biol. Chem. 279, 51953-51957. doi: 10.1074/jbc.M407001200

Valdivia, R. H. (2004). Modeling the function of bacterial virulence factors in Saccharomyces cerevisiae. Eukaryot. Cell 3, 827-834. doi: 10.1128/EC.3.4.827-834.2004

Von Pawel-Rammingen, U., Telepnev, M. V., Schmidt, G., Aktories, K., Wolf-Watz, H., and Rosqvist, R. (2000). GAP activity of the Yersinia
YopE cytotoxin specifically targets the Rho pathway: a mechanism for disruption of actin microfilament structure. Mol. Microbiol. 36, 737-748. doi: 10.1046/j.1365-2958.2000.01898.x

Wurtele, M., Wolf, E., Pederson, K. J., Buchwald, G., Ahmadian, A. R., Barbieri, J. T., et al. (2001). How the Pseudomonas aeruginosa ExoS toxin downregulates Rac. Nat. Struct. Biol. 8, 23-26. doi: 10.1038/83007

Yoon, S., Liu, Z., Eyobo, Y., and Orth, K. (2003). Yersinia effector YopJ inhibits yeast MAPK signaling pathways by an evolutionarily conserved mechanism. J. Biol. Chem. 278, 2131-2135. doi: 10.1074/jbc.M209905200

Zhang, T., Lei, J., Yang, H., Xu, K., Wang, R., and Zhang, Z. (2011). An improved method for whole protein extraction from yeast Saccharomyces cerevisiae. Yeast 28, 795-798. doi: 10.1002/yea.1905

Zhang, Y., and Barbieri, T. J. (2005). A Leucine-Rich Motif Targets Pseudomonas aeruginosa ExoS within Mammalian Cells. Infect. Immun. 73, 7938-7945. doi: 10.1128/IAI.73.12.7938-7945.2005

Conflict of Interest Statement: The authors declare that the research was conducted in the absence of any commercial or financial relationships that could be construed as a potential conflict of interest.

Copyright (c) 2017 Bankapalli, Mishra and Raychaudhuri. This is an open-access article distributed under the terms of the Creative Commons Attribution License (CC $B Y)$. The use, distribution or reproduction in other forums is permitted, provided the original author(s) or licensor are credited and that the original publication in this journal is cited, in accordance with accepted academic practice. No use, distribution or reproduction is permitted which does not comply with these terms. 